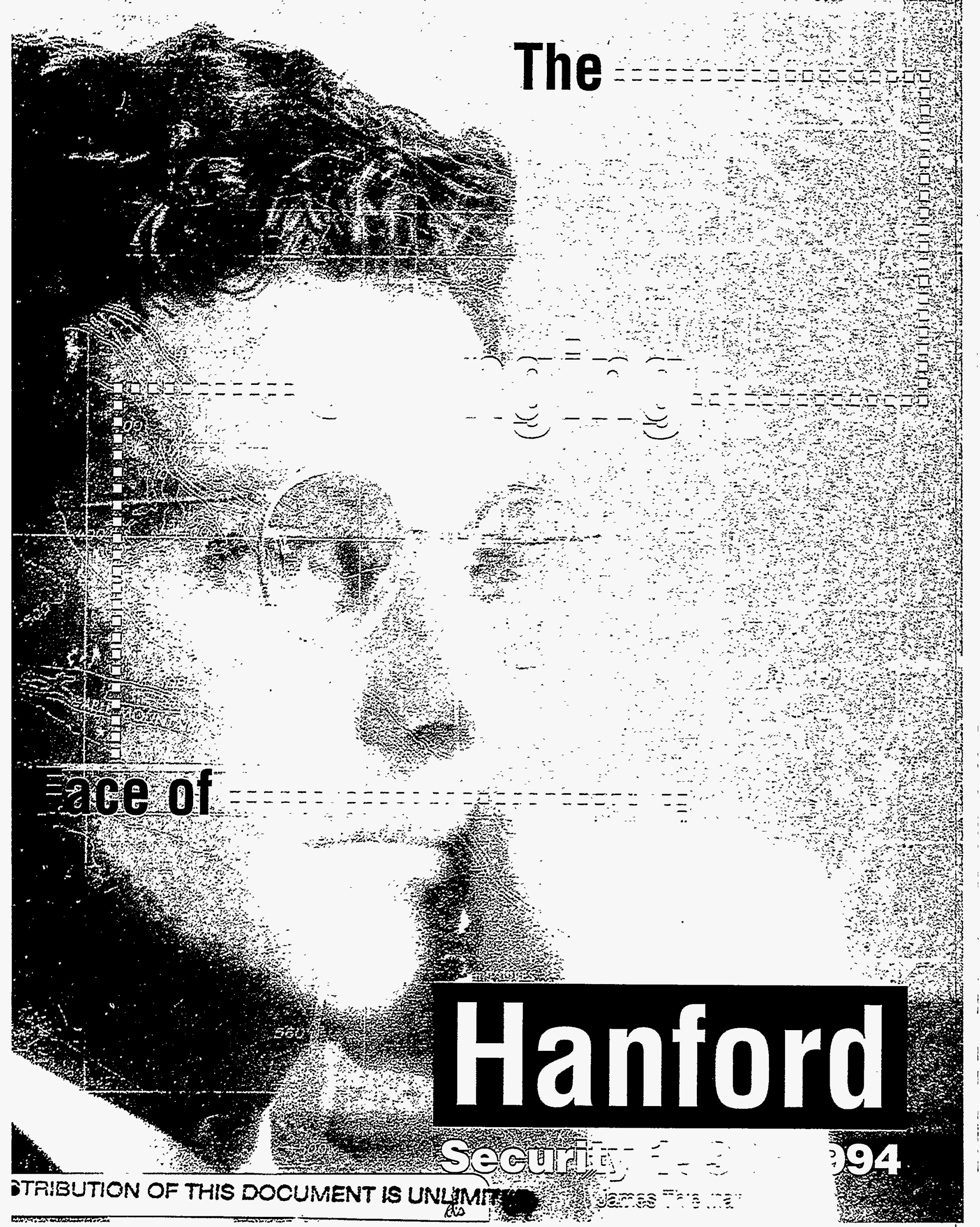




\section{Lessons of Transition}

\section{for Change:}

- Champion a new vision

- Use full-time teams

- Make visible changes

- Benchmark the best

- Empower the workforce

- Align DOE Orders with the mission

Introducing change into an organization requires a close look at the local situation. However, six general lessons can be drawn from Hanford's security transition.

\section{Top management must} champion a new vision.

Once top management at the site and at Department of Energy (DOE) Headquarters agreed to the changes, dramatic results occurred. For example, Richland Operations Office (RL) Manager, John Wagoner, championed the clearance reduction effort that cut Q clearances by $83 \%$ over three years. Bob Rosselli, Assistant Manager of Administration, was a steadfast champion of the changes. Joe Wiley, manager of the transition, accompanied Rosselli on a visit to Headquarters that gained additional support.

Free up full-time teams to focus on change and provide them with resources.

Between October 1991 and October 1994, DOE Safeguards and Security empowered teams to work full time on security transition. Full-time workers get more done and have a broader perspective. The first team spent three months planning changes that were reviewed by a second team in a six-week period. A third team, the Security Transition Program Office (STPO), was given two years to implement the changes. DOE provided initial funding for the STPO; additional fund-ing came from savings gained through implementing change.

\section{Make visible changes early on.}

Formed in September 1992 the STPO immediately discontinued badge checks on people leaving the site. By the end of March 1993, badge checks by Hanford Patrol personnel ended at many points across the site. The visible changes announced to all that change could and would occur.

\section{Benchmarking trips provide new approaches.}

When Hanford staff visited other companies, they gained a feel for industrial-style security. Particularly helpful was a visit to the Boeing Company in Seattle. Comparing Hanford security to security at private sites improved or validated security transition approaches.

Empower workers to contribute to change.

Security transition took steps to involve employees in the change effort. Workshops to redesign processes brought the people doing the work together to suggest improvements. Moreover, the transition has led to each employee's assuming greater responsibility for security. The new approach was validated in a recent inspection and evaluation.

\section{Align DOE Orders with the new mission.}

The local interpretation and execution of DOE Orders are key cost drivers at DOE sites. A map through the labyrinth of Orders was created so the team could quickly see which Orders applied to protecting a particular asset. This tool proved useful in peeling back layers of protection that went beyond the minimum required. 


\section{DISCLAIMER}

Portions of this document may be illegible in electronic image products. Images are produced from the best available original document. 



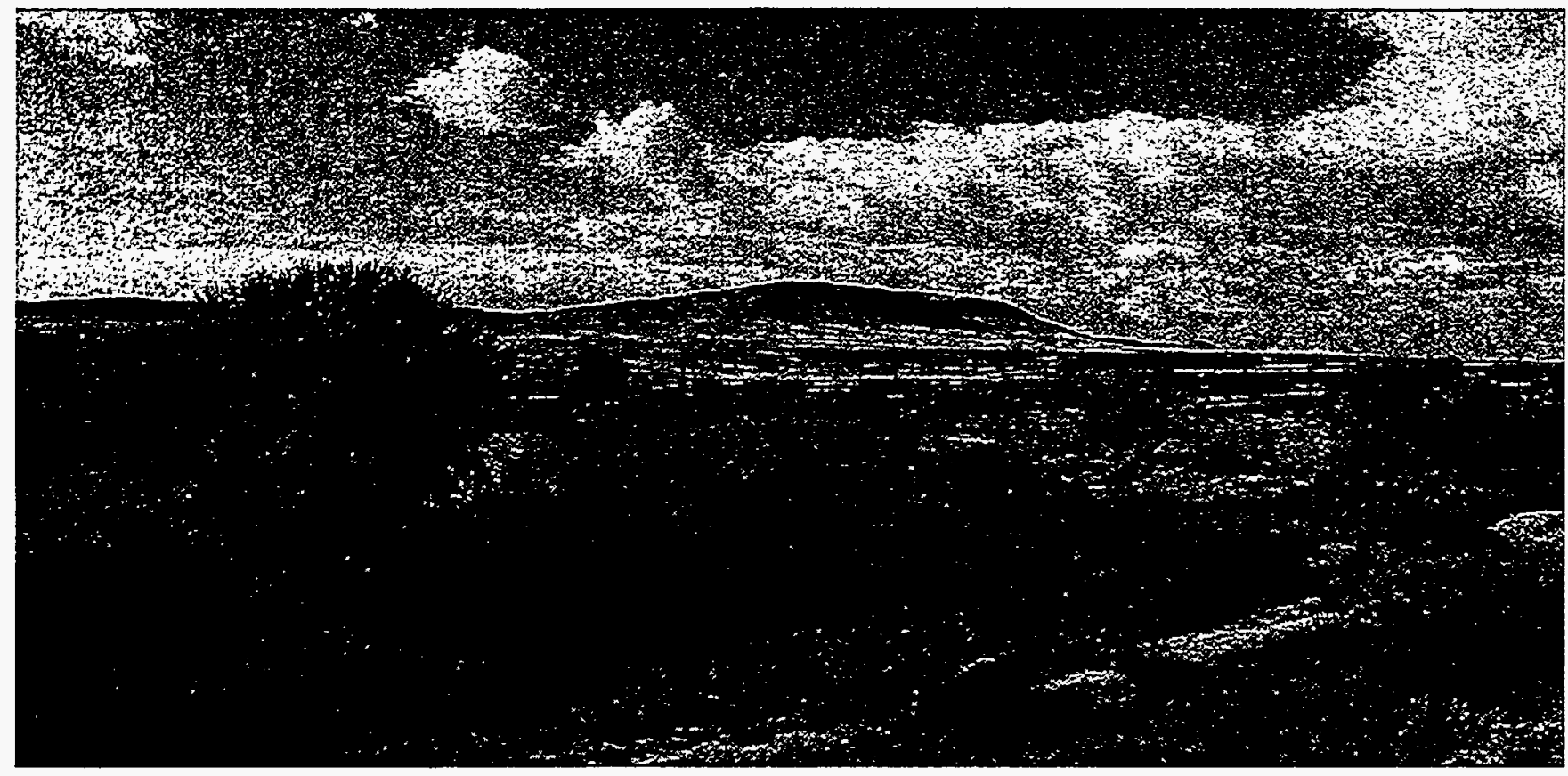

\section{Summary}

The meltdown of the Cold War was a shock to the systems built to cope with it. At the DOE's Hanford Site in Washington State, a worldclass safeguards and security system was suddenly out of step with the times.

The level of protection for nuclear and classified materials was exceptional. But the cost was high and the defense facilities that funded security were closing down. In their place, an environmental cleanup mission was growing, demanding easy access for workers without security clearances.

The defense mission had created an umbrella of security over the sprawling Hanford Site. Helicopters designed to ferry special response teams to any trouble spot on the 1,456 square-kilometer (560 squaremile) site made the umbrella analogy almost literally true. Facilities were grouped into areas, fenced off like a military base, and entrance required a badge check for everyone. Within the fence, additional rings of protection were set up around security interests or targets.

Airport-style metal detectors were used at some points. Hand-carried items were opened for inspection, and occasionally a "lock down" occurred, with careful and time-consuming searches slowing entrance or exit. The security was effective, but costly to operate and inconvenient for employees and visitors alike.

Moreover, the umbrella meant that virtually all employees needed a security clearance just to get to work, whether they worked on classified or unclassified projects. Clearly, some fundamental rethinking of safeguards and security was needed.

But the culture developed over decades of the defense mission made change difficult. The Hanford Site grew up with the Cold War, and the change would be as challenging as any transition faced by large corporations. The effort to meet that challenge is the story of transition at Hanford. 


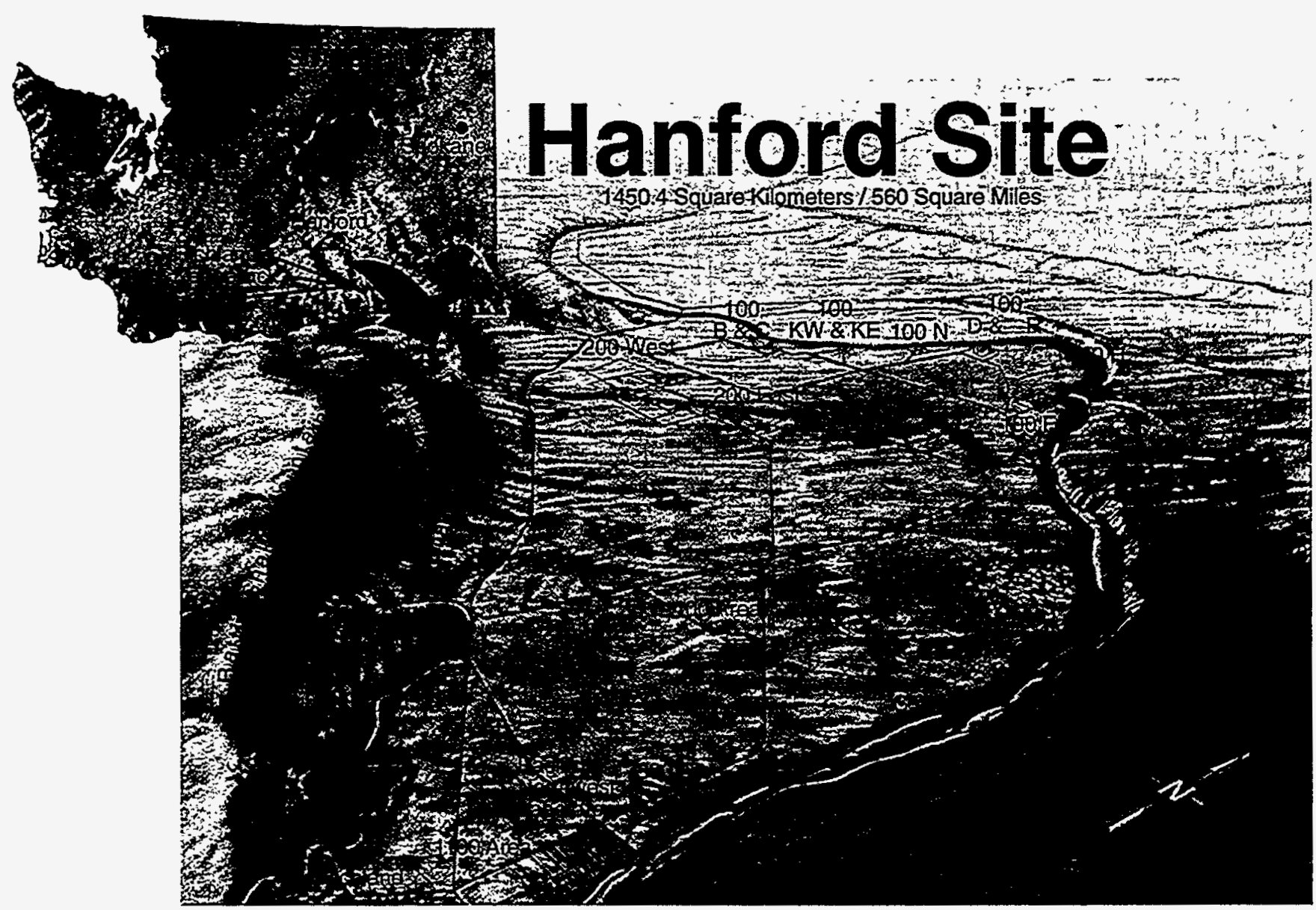

\section{Overview}

The Hanford Site lies on arid tableland between a sweeping bend in the Columbia River to the north and Rattlesnake Mountain to the south.

The site was selected in 1943 for the construction of reactors and production plants for making nuclear weapons materials. Workers fabricated fuel for the plants in the 300 Area just north of the City of Richland (see map). Reactors, strung along the bend in the river (100 Areas), irradiated the fuel. Facilities on the. central plain of the site
(200 Areas) extracted plutonium from the irradiated fuel, and the resulting materials were sent for further steps in weapons production. Wastes accumulated at various locations around the site over the next five decades.

The site is home to the Fast Flux Test Facility (400 Area), a remnant of breeder reactor research.

The DOE manages the site and multiple contractors including Westinghouse Hanford Company, the management and operations contractor;
Pacific Northwest Laboratory (PNL), a multipurpose federal laboratory operated by Battelle Memorial Institute; and Hanford Environmental Health Foundation.

\section{A History of Secrecy}

Secrecy and security were watchwords from the beginning of Hanford's defense mission because of the ongoing war effort. During the Cold War that followed, the Soviet Union provided a credible threat to security interests, so high security and 
secrecy continued to be watchwords.

The Hanford Patrol was created early on and empowered to control access to the site. A large Safeguards and Security organization provided high-level protection for special nuclear materials and classified information. Safeguards developed systems to guard against diversion of nuclear materials by insiders and security focused on controlling access to the site.

\section{An Event in} Munich

By the 1970s, security at the site involved badge checks at gates by Hanford Patrol personnel armed with pistols. An event in 1972, a continent away, changed security at Hanford and other government facilities. At the summer Olympics in Munich, Germany, terrorists murdered nine Israeli athletes. Security guards watched but did nothing as the terrorists, dressed in ordinary sweat suits, climbed over the fence with deadly weapons concealed in athletic bags. The guards were accustomed to athletes breaking curfew and sneaking back to their quarters. Once out of sight of the guards, the terrorists donned masks and went on with their deadly mission.
The event gained the attention of security forces and Congress. At Hanford, security managers soon questioned whether the existing force could deal with a dedicated team of terrorists. A protective force armed with pistols would be no match for terrorists with automatic weapons. Thus began a buildup in security at Hanford and other DOE sites that continued during the 1970s and was intensified in the 1980s, during President Reagan's defense buildup.

\section{Following Orders}

For a time, the security program even became a separate line item in the budget-an independently funded program. Later, the security budget was folded back into programs, especially Defense Programs. Thus the Safeguards and Security (SAS) organization sought funding from programs that were producing nuclear materials. Federal Orders, which give criteria for federal facilities, provided the SAS program with the lever to gain funding.

Where weapons materials were involved, the criteria required planners to assume that a major breach of security would occur and to prepare for it.
The DOE Orders were written at various times, with new and revised Orders appearing regularly. Often, Orders overlapped each other. Thus they overlaid on management a series of requirements that were difficult or impossible for one individual to understand. To meet the requirements, management hired people to become expert in the various Orders. When a new program began, the manager simply referred to the experts to find out how to meet requirements. Each expert would provide requirements based on the Orders he or she knew.

The result was that a security interest at Hanford was often protected by layers of security. This approach fit well with a nuclear site, for redundant protection was the philosophy throughout that industry. If one Order said to protect classified documents with an alarm system, another said to use a locked repository, and a third said to have a log system checked daily by security personnel, Hanford would have all three approachesalthough the intent might have been to use one of these approaches. Enterprising staff trying to do a good job might add additional layers, because the focus was on effectiveness, not cost. 


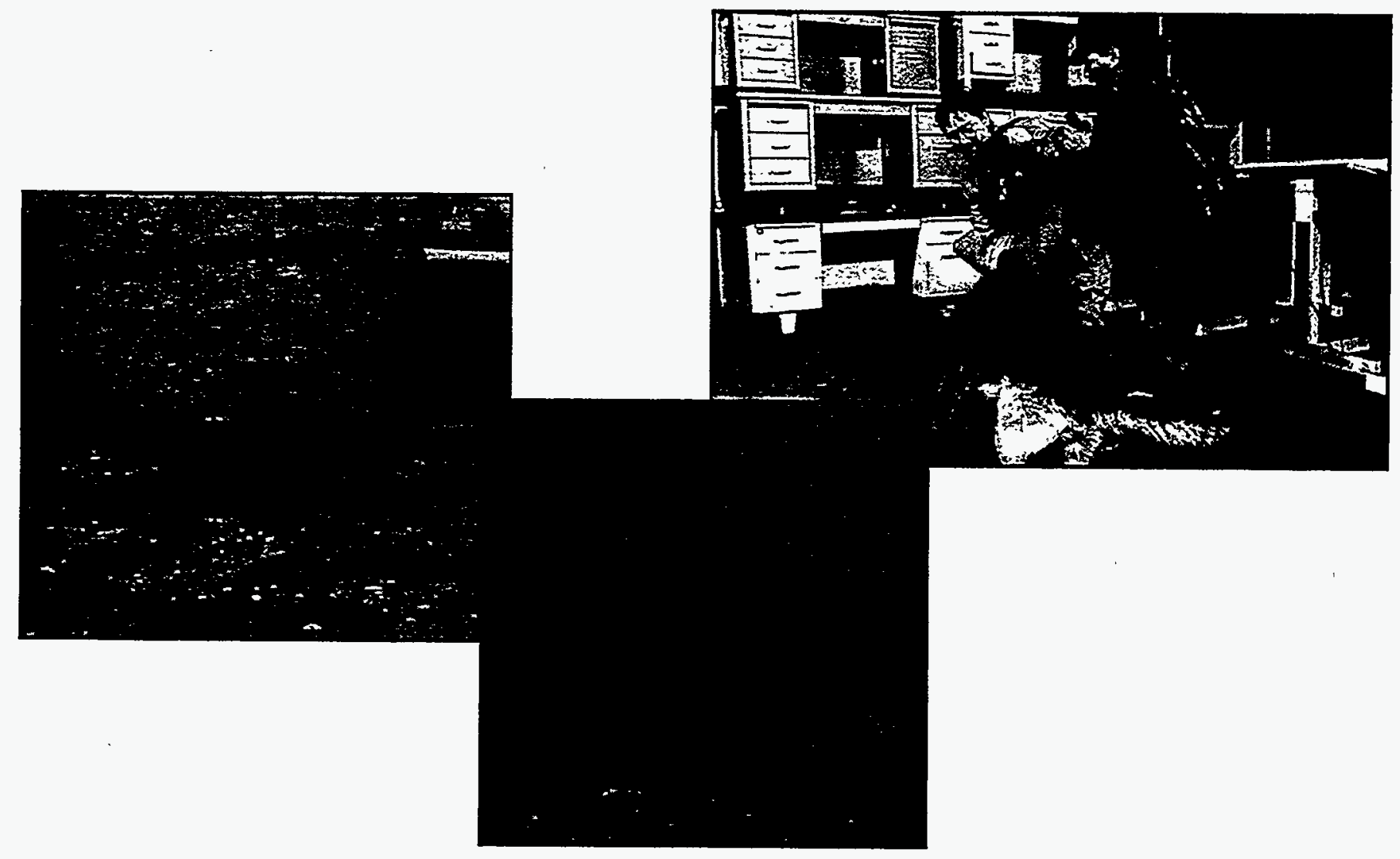

Hanford Patrol's special response team trained to maintain readiness during the Cold War.

\section{An Independent Review of Security}

In spite of the layers of security, the first independent review of Hanford's Safeguards and Security program by the federal Office of Inspections and Evaluations in 1979 turned up deficiencies. Security interests were spread around the sprawling site. Six highly controlled protected areas had to be guarded: a fuel fabrication plant in the 300 Area; the 400 Area's Fast Flux Test Facility; the 200 Areas' Plutonium-Uranium Extraction (PUREX) plant, Plutonium Finishing Plant, and Critical
Mass Laboratory; and the 100 Area's N Reactor. Some highlevel interests were separated by as much as 40 miles.

\section{Response to Findings}

To get to the high-security areas quickly and to be effective at dealing with the potential threat, Hanford needed a highly mobile, heavily armed special response team. Security professionals set up programs to develop, train, and equip this team. They purchased armored personnel carriers along with a smaller, military version of a dune buggy. The Special Response Team was armed with automatic weapons and given extensive training in counter-terrorist tactics. Hanford's security force was being transformed into a paramilitary organization.

To ensure that the Special Response Team was highly mobile and to provide aerial surveillance of the extensive Hanford Site, two helicopters were added in 1983. The helicopters could deliver the Special Response Team when and where they were needed, while backup in armored 


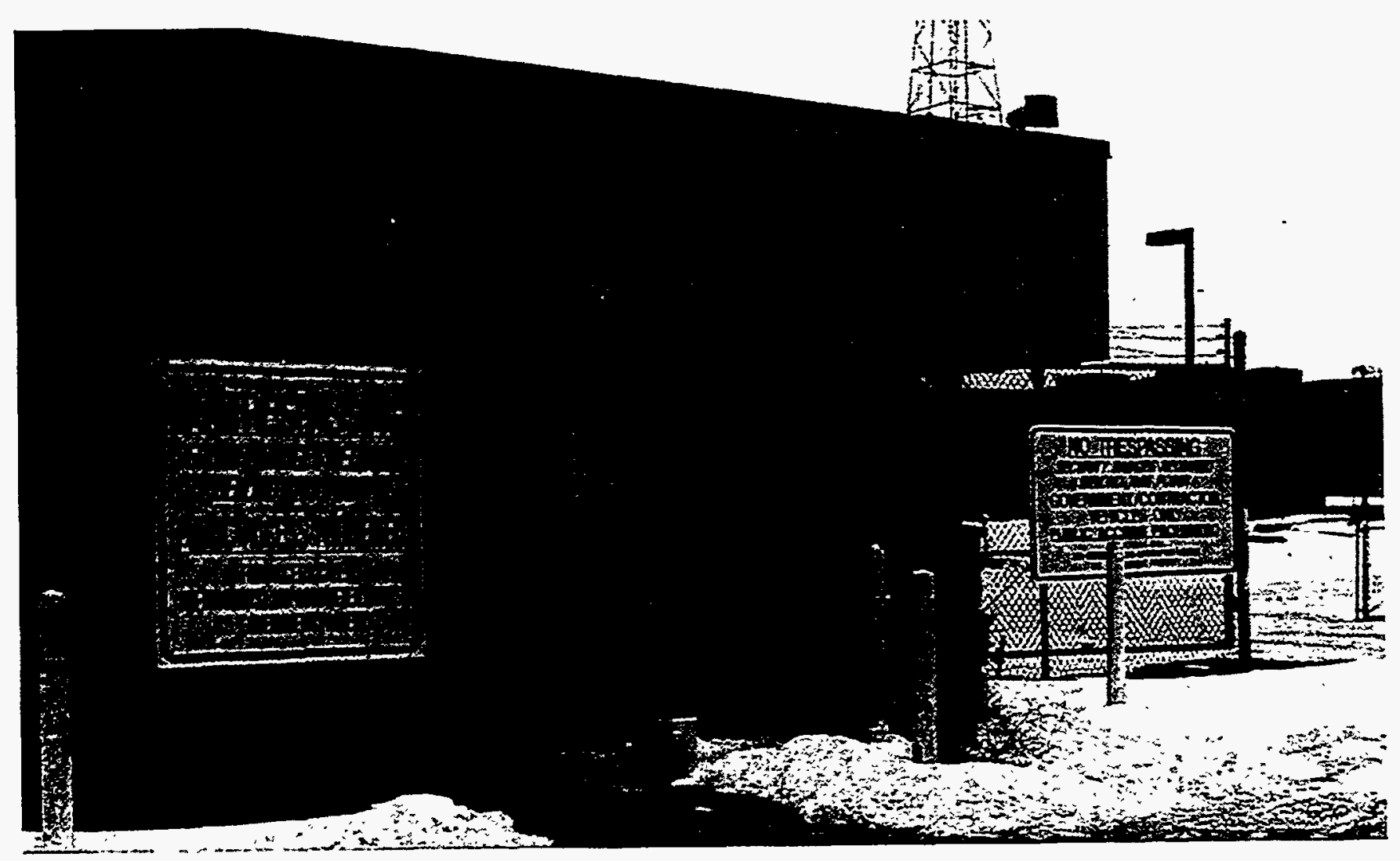

The Hanford Patrol no longer checks employees with metal detectors at this badge house near the Fast Flux Text Facility. Instead, signs remind employees and visitors that they must have an identification badge to enter the area.

vehicles would follow. The alternative, locate highly trained ground forces at each area, was rejected as too expensive.

Exercises were run frequently, so it was not uncommon for employees working late to encounter heavily armed teams dressed in camouflage, carrying MILES laser equipment, and communicating via walkie-talkie as they swept across an area and through buildings, preparing for any eventuality. Occasionally, annoyed scientists complained of the overzealous searches. But armed with DOE Orders and congressional and public concerns about terrorism, Safeguards and Security continued its effective, if expensive, programs.

Even then, critics of the system noticed that at Hanford, special nuclear materials were guarded by armored personnel carriers and helicopters when moving between one area and another. The same materials were then loaded on DOE Safe-Secure Transport trucks and driven across the country without that level of protection.

\section{Other Directions}

At the same time, events began pulling the Hanford Site in another direction. The Reagan effort to privatize much of the federal bureaucracy was in vogue. When managers looked at finding private investors for facilities like the Fast Flux Test Facility, a clear obstacle was the $\$ 13$ million in related security costs. So, at the same time that a major security buildup was under way, the seeds of change were being sown. 


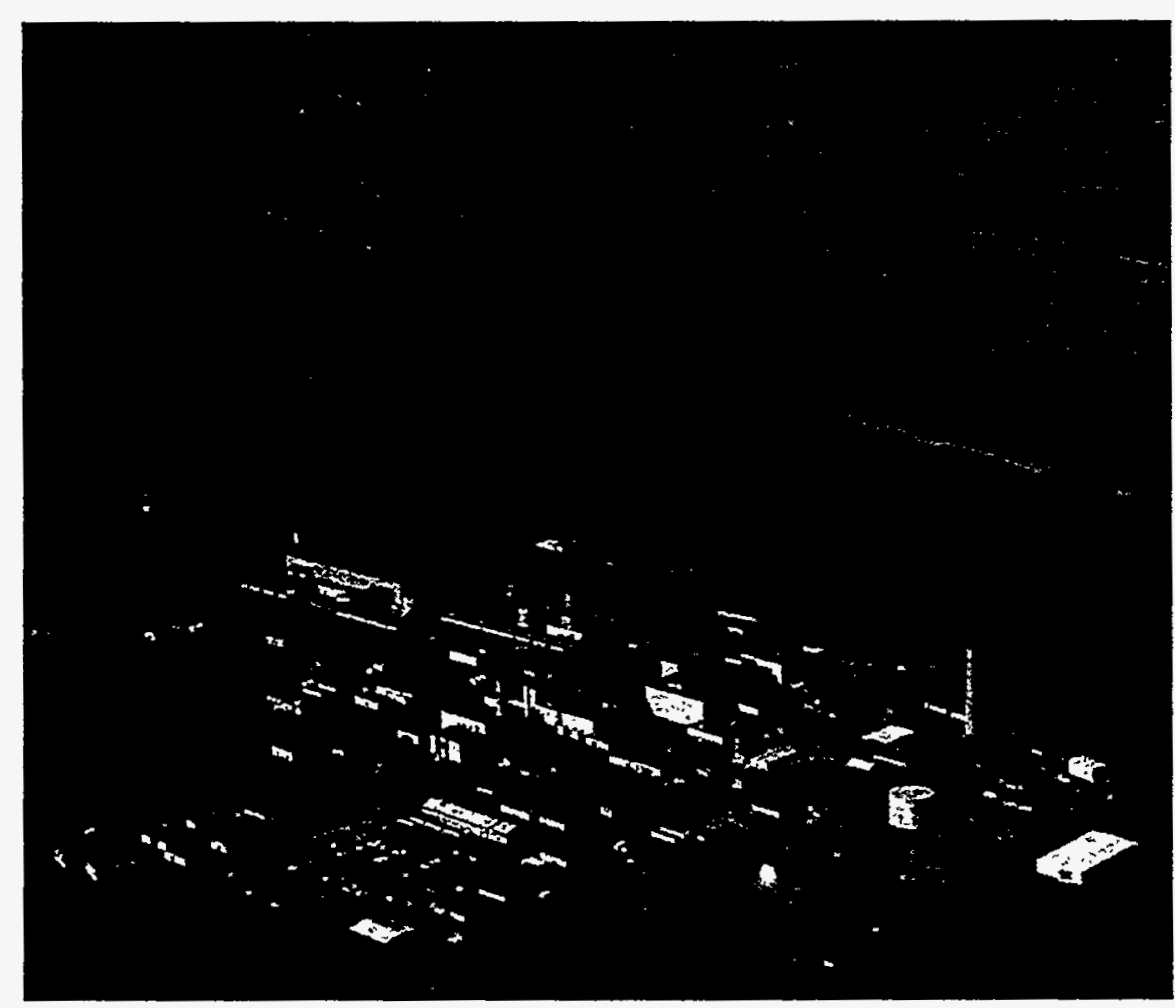

An aerial view of the $N$ Reactor, retired in 1991. Its primary mission was production of special nuclear materials for national defense. With the defense mission ended, security needed to be aligned with the cleanup mission.

And in spite of the upturn in defense budgets, by the mid1980s Hanford leaders began to sense that the defense mission might not last forever. In 1987, the Pacific Northwest Laboratory, the research arm at Hanford proposed a Molecular Science Research Center. The proposal was an effort to bring a major nondefense program to Hanford to anchor federal dollars there when the defense mission went away. The program began to bring many visiting scientists to Hanford. PNL leaders complained about the security restrictions, which response, Lawrence sought to involve the public in the decision-making process related to cleanup of wastes and to the study of potential health effects from past operations.

This latter study, known as the Hanford Environmental Dose Reconstruction project, required a massive declassification effort that continues today. The study and the declassification intensified public concerns about waste remaining on site. The reduction in classified information resulted in less material that needed to be protected. Both factors would impact security.

For all three major contractors-PNL, Westinghouse Hanford, and Kaiser Engineers-environmental cleanup began to loom as a potential new mission. But, if environmental subcontracts were let, how would the contractors find enough workers with the highlevel clearances needed to get around on the site? Security had to change.

During Michael J. Lawrence's tenure as manager of $R L$, Hanford had opened up much of its history to public scrutiny. Environmental groups attacked Hanford's nuclear production mission and the legacy of complex wastes; they expressed concerns about health effects from past operations. In

\section{The End of the Defense Mission}

The vulnerable defense mission's demise was hastened by world events. In April 1986, an experiment went awry at the 
Chernobyl nuclear plant near Kiev in the former Soviet Union. A meltdown occurred and the graphite core of the reactor caught fire, spewing radioactive contamination into the atmosphere.

Alone among U.S. reactors, DOE's N Reactor had a graphite core. Although local experts would argue that the designs of the Chernobyl and $\mathrm{N}$ reactors differed, the term graphite core ignited the public imagination. Soon DOE was funding studies of the impacts of shutting down the $\mathrm{N}$ Reactor permanently.

With that prospect in sight, the search for new missions intensified. But some of the factors that led to the end of the defense mission, also led to the beginning of the environmental mission. With the collapse of the Soviet Union, the fall of the Berlin Wall, and the reunification of Germany as a democratic state, the United States became the sole nuclear-armed superpower. As Soviet influence decreased, the need for an extensive nuclear arsenal diminished.

In 1989 , Secretary of Energy

Watkins declared that Hanford's defense mission had ended. He stated that the nuclear materials at Hanford would not be needed or used for nuclear weapons. Thus, the defense mission was truly over. This change alone would mean a change in the security needs at Hanford.

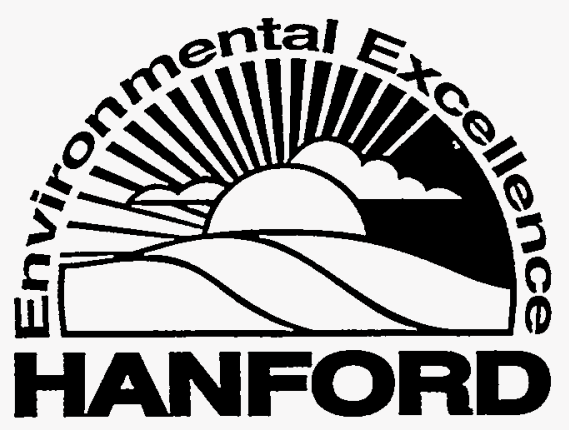

The Beginning of the Environmental Mission

The DOE had prepared a major evaluation of cleanup options for Hanford that included everything from doing nothing to doing a complete cleanup of the site. As part of this effort, the number of waste sites and amount of waste on the site were evaluated. The statistics were staggering: over 1100 waste sites and billions of cubic feet of soil contaminated with low levels of hazardous and/or radioactive materials. Complex wastes were stored in tanks and some of them had leaked into the desert subsurface.

Public concern about Hanford and the entire complex of DOE defense facilities led to the creation of a special Office of
Environmental Restoration and

Waste Management. This

program quickly became the largest at Hanford.

During this period, the DOE lacked public credibility in the safety arena. Secretary Watkins made an all-out effort to reassure the public that safety would come first. Tiger Teams evaluated every DOE site and facility with a view toward safety. Environmental cleanup was part of the safety story-it would provide for public safety over the long term. But the environmental program did not want to be saddled with security costs predicated on defending mostly closed defense facilities. N Reactor and the production facility known as PUREX were both shut down by 1990 . Only three major facilities were left: the Plutonium Finishing Plant, the Fast Flux Test Facility, and fuel fabrication facilities in the 308 Building.

Faced with changes on many fronts, security management recognized that changes in its programs were inevitable.

Rather than wait for a budget cutter armed with a percentage goal to hack away at programs, SAS management sought to lead a planned security transition. They proposed that RL Manager Mike Lawrence 


\section{A dramatic reduction in protected areas enables industrial-style security at Hanford}
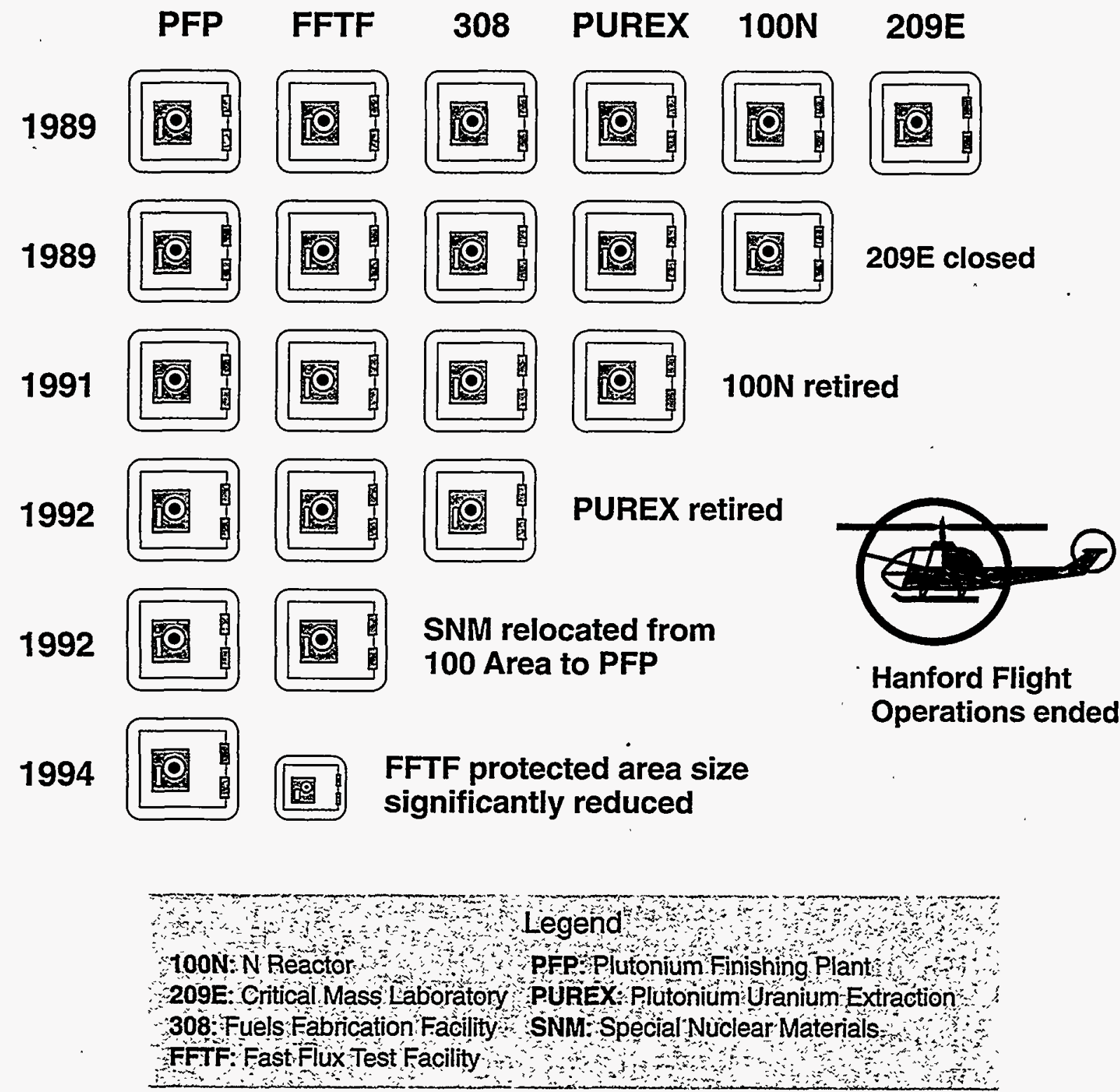

The mission change at Hanford was followed by a reduction in the number of protected areas. Special nuclear materials were consolidated into two areas by mid-1992. At that point, aerial patrol of Hanford by helicopters ended. The security force was further decreased in 1994 when the size of the protected area at the Fast Flux Test Facility was reduced, leaving only one protected area with the same level of security as in the past. The consolidation of materials made it possible to envision industrial-style security for most of the site. 
convene a week-long meeting with his assistant managers and propose changes in security to match the new mission.

\section{Crystal Ball Begins}

Approving the concept, Lawrence, however, believed the best approach was to turn the effort over to the operations contractor. In a May 1990 letter, he termed the effort Crystal Ball and directed that it be headed by Westinghouse's strategic planning group. Westinghouse assembled a small team and set to work over the summer of 1990.

The Crystal Ball team held weekly meetings to discuss the proposed transition from a defense security posture to an industrial posture, with additional protection for remaining nuclear materials and classified information. The team quickly identified the major opportunities: consolidate security areas and programs; reduce clearances; simplify access; and use technology, including automation, where feasible to improve security and lower costs.

Efforts to consolidate special nuclear materials were already in progress, driven largely by the mission change. In the 1980s, there were six protected areas. At the time of the Crystal Ball effort that number was down to four. The Crystal Ball report suggested cutting those down to two, the Plutonium Finishing Plant and the Fast Flux Test Facility. This recommendation would mean closing down a fuel fabrication facility in the 308 Building of the 300 Area and closing the protected area at PUREX.

The savings from consolidating materials is significant. Each protected area requires high-level security with metal detectors, radiation monitoring equipment, and several armed security guards on a 24 -hour basis. Reducing the number of protected areas provides major savings. If the protected areas were consolidated, aerial patrols by helicopter might also be eliminated, according to the Crystal Ball Strategic Plan.

For such changes to take place, the Crystal Ball team needed only the concurrence of the operations contractor, Westinghouse Hanford. The team soon discovered that when their suggestions affected several contractors, it was difficult or impossible to get agreement. One idea would have consolidated clearance processing with Westinghouse Hanford. This idea and others were dropped from the Crystal Ball report when it became clear that they would not make it through a steering committee sign-off process that required consensus from major contractors.

The initial Crystal Ball report was signed off by the contractors at the end of September 1990. The Crystal Ball team had not attempted to make any changes, simply to offer a plan for change. But others saw the need for action and were frustrated, wanting to get on with the work. They soon found a powerful ally - the Crystal Ball team briefed the new RL Manager, John Wagoner, on November 9 , 1990. In a letter dated December 7, 1990, Wagoner referred to the Crystal Ball effort. "We have to aggressively pursue further initiatives in this area."

\section{Clearance}

\section{Reduction}

Several people at the briefing suggested to Manager Wagoner that clearances needed to be reduced. "Not reduced," Wagoner replied, "Eliminated." He was ready to move rapidly in this area especially. He proposed an across-theboard $90 \%$ reduction of $\mathrm{Q}$ clearances as a target. Up to that point, clearance reduction 
had been discussed and minor progress had been made. The $90 \%$ goal was a bold move designed to break free from a gradualist approach to clearance reduction and make significant reductions quickly.

In a separate letter on the clearance reductions, Wagoner asked that the reduction take place over about six months. The two smaller contractorsKaiser Engineers and Hanford Environmental Health Foundation actually reached this ambitious goal. The larger contractors-Westinghouse Hanford and PNL_would take longer to approach the goal.

Key to clearance reduction was developing accurate reporting of the progress. For some time, the contractors had been reporting reductions in clearances, but not against any baseline. While clearances would go away, new employees might get new clearances; and there might be no net reduction. New reporting requirements were designed to capture the true picture-the total number of $Q$ clearances going away:

July 1990 was used as the baseline. At that time there were $10,235 \mathrm{Q}$ clearances and 2,663 L clearances. The data began to show a significant

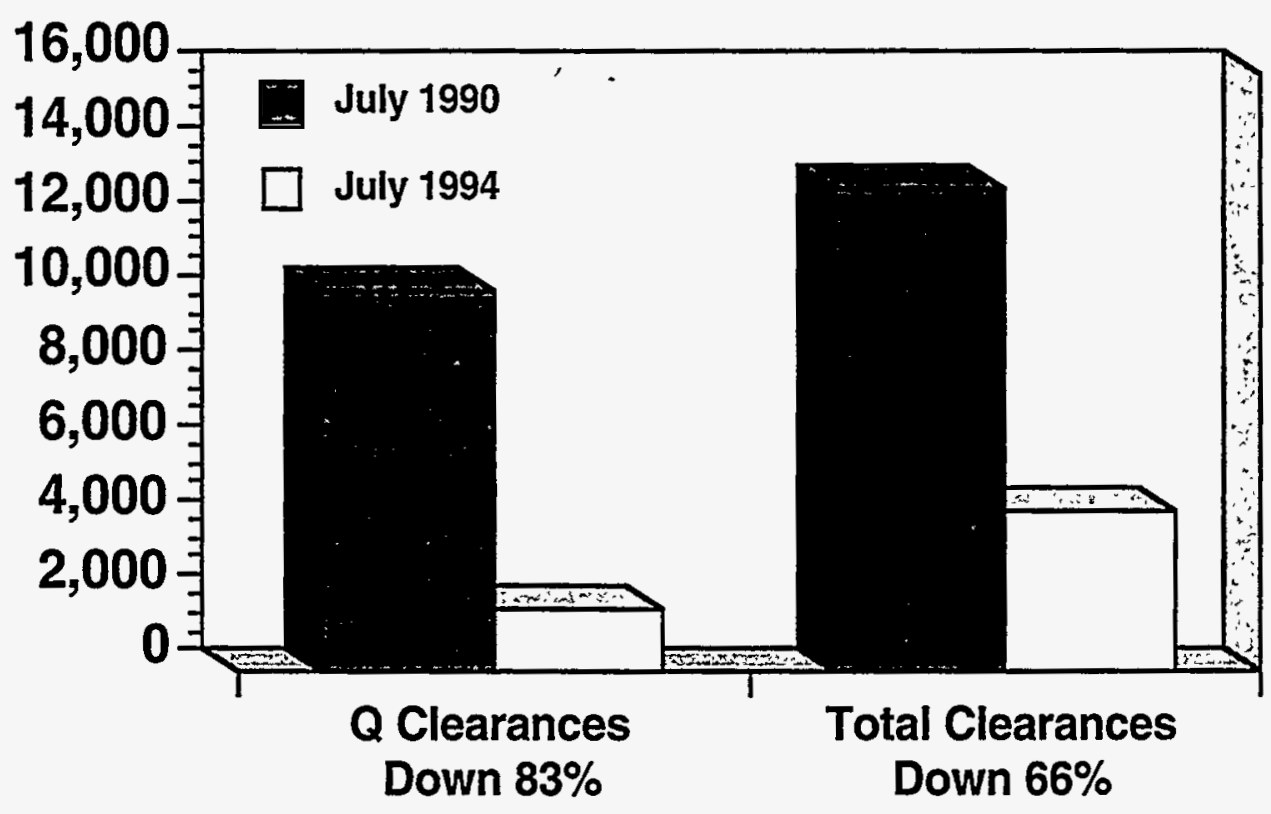

Richland Operations Office Manager John Wagoner set a goal-reduce $Q$ clearances by $90 \%$, saving millions of dollars.

reduction in Q clearances over the coming months. Initially, while $Q$ clearances decreased, $\mathrm{L}$ clearances increased. That was still major progress. The cost to check for an L clearance is about $\$ 43$. On the other hand, $Q$ clearances require a thorough background checkincluding extensive interviews with associates, friends, and neighbors. An initial Q clearance costs about $\$ 2,800$ and a reinvestigation, which is needed every five years, costs $\$ 1,600$.

Conservative estimates placed savings from the clearance reduction effort at more than $\$ 6.1$ million by the end of FY 1993. Cumulative savings were much higher. The budget for clearances was nearly $\$ 5$ million in 1990; today it is less than $\$ 1$ million.

\section{Crystal Ball Implementation Plan}

Meanwhile, in January 1991 a reformed Crystal Ball committee set out to develop an implementation plan. The plan was completed and submitted to Wagoner in May 1991. It emphasized the consolidation of special nuclear materials so that the number of protected areas could be reduced further. Some of this reduction had been going on anyway as operating plants were shut 
down. For example, the shutdown of $\mathrm{N}$ Reactor and PUREX meant two less protected areas.

A year had passed since the letter calling for the first Crystal Ball committee and the results to date were plans but no action, except in areas where Manager Wagoner had focused attention: the clearance reduction effort was making headway, and the consolidation of materials and reduction of protected areas was proceeding. These successes were in response to Wagoner's direction and emphasis.

In the final analysis, the Crystal Ball team could have only limited success because it did not have the power to make change happen. Where Crystal Ball had surfaced ideas and Manager Wagoner had directed the site to make changes, the changes were occurring. The lesson was clear. If change was to be made, DOE-RL must direct it.

\section{A Security Planning Team}

The difficulty in getting DOE leadership more involved in the transition was the time factor. The greater the power of the leaders, the less time they had to focus on one issue.

The lesson was clear. If change was to be made, DOE-RL must direct it.

What was needed was a detailed look at the program by people freed up to do nothing else. As the Crystal Ball effort ended, Security Director Joe Wiley asked one of his branch chiefs to lead an effort to examine the entire SAS organization and make recommendations. The branch chief was tasked with taking a fresh look at the organization, putting on a new pair of glasses and trying to see how security should work in the new environment. He created a three-person Security Planning Team to work on an in-depth examination.

Each member of the team brought special skills that would prove useful in the task that lay ahead. One brought investigative ability; another vision, technical background, and management skills; and a third financial acumen. All these skills would be needed along with the team's shared knowledge of how Hanford works. This was to be a team of security insiders charged with going to the bottom of the organization and digging out the facts about how the operation was doing.

All three team members also shared a disciplined, logical, businesslike approach to problems. They believed that only by digging in and finding the facts would they keep their recommendations from becoming just another study followed by no action or worse, the wrong action.

A critical success factor was getting the three people on the Planning Team freed up to dedicate their time to this effort. Experience told the team that if their attention was divided, they would never accomplish the task. Taking a fresh look requires freeing up the imagination by breaking out of harness.

\section{Setting Up Shop}

The Planning Team looked at safeguards and security at Hanford. They began by setting some ground rules for themselves. They were determined to present enough data for management to make informed decisions. But gathering the facts was not a simple matter.

The difficulty in obtaining the facts resulted from budgets 
structured by organization rather than by activity. Security is a service funded by programs and pools. About a dozen programs and funding pools are listed in security budget tables. It is easy to see how much is being spent on security, and even to break that down by security organizations. So it was easy to answer how much was spent for a protective force at a facility. But it was almost impossible to say how much was spent protecting classified information at Hanford. It was also difficult to determine how much was being spent on the number one job-protecting the public from theft or diversion of nuclear materials versus how much was spent on the rest of the security program. The difficulty was that within the organizations and job descriptions, people performed more than one. function.

To solve the problem, the Planning Team devised a matrix to use in interviews with each security manager across the site. The matrix captured activities in column headings and security organizations in row headings. In the meetings, managers were asked to identify the areas where their people worked and then to estimate how much effort in hours or dollars they spent in each area. The result would be a clear view of costs by activity.

Meanwhile, one member spent much of his effort in walking the site and observing how security functioned in practice. Sometimes the others accompanied him. He toured every location where a security interest was kept and spoke with those responsible for protecting the asset. The discussions with managers and the site tours surfaced many ideas for improvements.

\section{Taking Action}

Unlike the Crystal Ball effort, this team was empowered to take action. Where changes could be made quickly, the team presented the ideas to Director Wiley, and the changes were made at once. For example, multiple classified repositories had been created over the years. In the 200 Areas, Wiley and the DOE-RL Manager of Programs were able to simply walk the site and in one day reduce the multiple repositories to one. This was the sort of effective change that some had wanted to make all during the Crystal Ball planning efforts.

\section{Challenging the Layers of Security}

A third part of the data collection was a look into the complex and lengthy collection of DOE Orders discussed earlier. As the team toured the site, they noticed that different contractors interpreted the Orders differently. The reason, of course, was that the Orders were not organized so a user could look up an asset and quickly see how to protect it.

One team member led the effort to cut through the confusion. He hired a person to analyze the Orders and provide a flow diagram, showing which Orders applied in specific situations. Using this tool, a person who needed to know how to protect a classified document could find out quickly which Orders applied. The Planning Team soon discovered that the Orders provided options.

At last, the team could challenge the use of layer upon layer of security, where simply meeting the requirements using a single option was sufficient. With a way to see through the complex Orders to the ones that applied to a particular situation, management would opt for the cost-effective solution. 


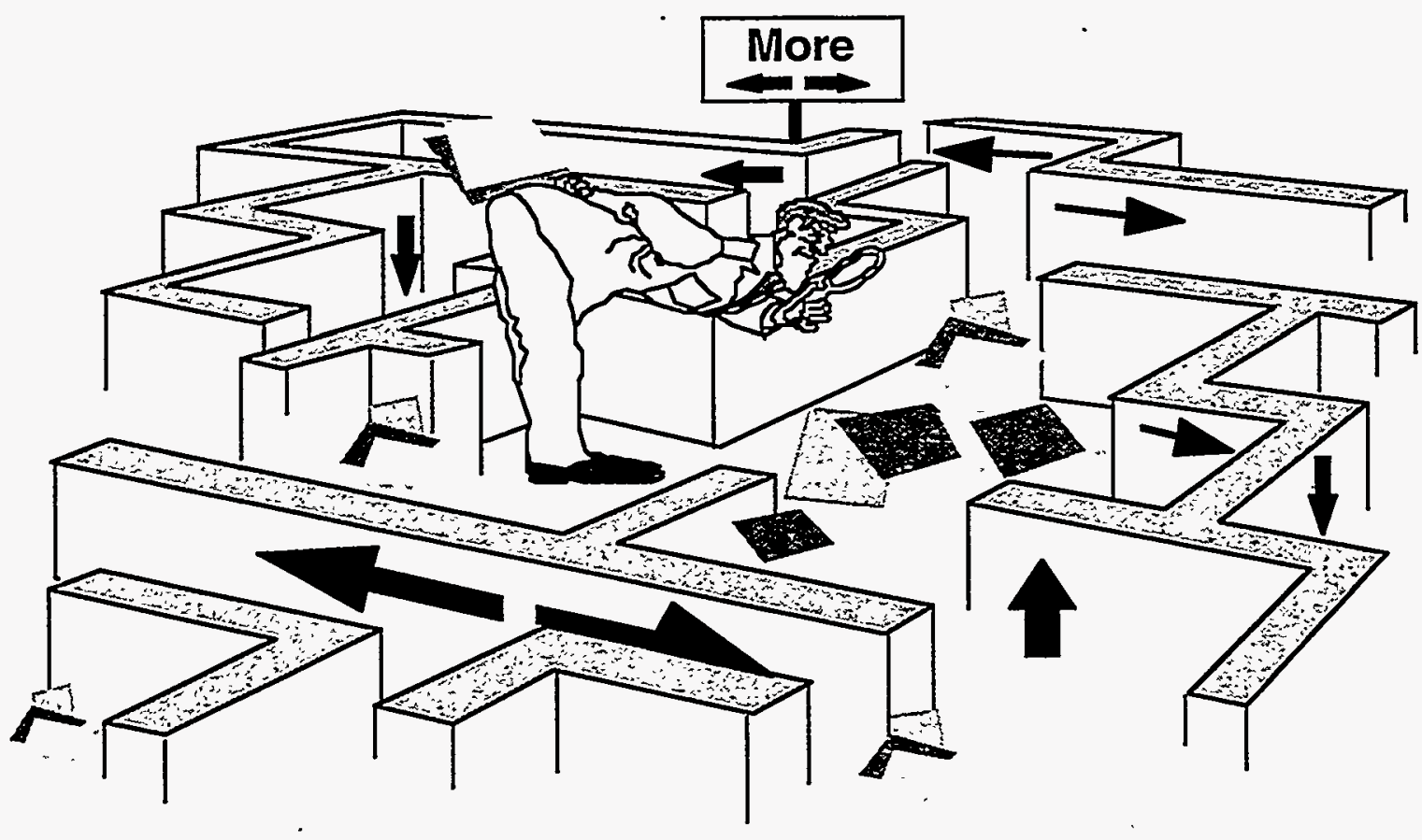

Searching the Maze of Orders

Developing a tool to guide users through a maze of Orders helped Hanford meet, but not exceed, requirements.

Such a tool was needed to effect change in a culture resistant to risk-taking. The culture that rightly developed around protecting the highestlevel interest at Hanford had spread to every comer of the site and was used to protect property as well as high-level interests. The tool for analyzing Orders empowered the team to make changes.

Eventually, such an approach empowers managers to take responsibility for the security applied to their assets. Ultimately, the security transition is an attempt to move the site in this direction-the same direction that management experts suggest for businessempower the managers and the employees to make decisions in their areas of expertise.

\section{A Three-Month Look}

The Security Planning Team continued with intensive efforts for three months. Often they would go back several times to the same manager. One team member would check some of the numbers against the financial tables to confirm their validity. The team was not making any determination about what should be done to change security at Hanford. They were simply gathering data. In late December and early January, they totaled the data (see chart, page 14). Then they began to form their conclusions and recommendations.

The data showed, for example, that Hanford was spending about $\$ 15$ million to protect the public from theft or sabotage of nuclear materials. 


\section{FY 1992 Funding Levels by Security Interest}

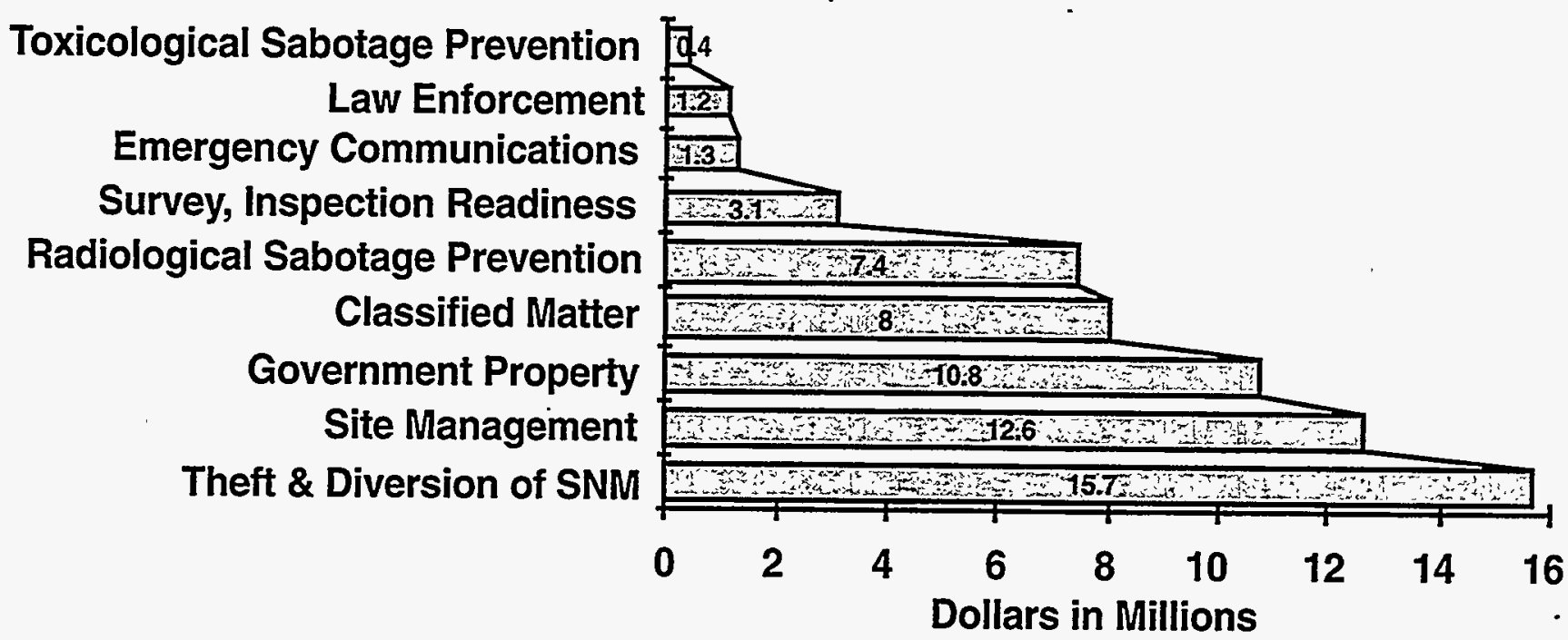

Data collected by the Security Planning Team clearly illustrated where changes could be made.

But another $\$ 12$ million was spent on site management, and nearly $\$ 11$ million was spent to protect government property, while losses hovered around $5 \%$ of that amount. The cost of protecting property was equivalent to spending $\$ 11$ to save five cents. Was that level of protection costeffective? This question, that a business would ask up front, had not been asked at Hanford-especially not by members of the safeguards and security team. As mentioned earlier, the question had surfaced during privatization studies and attempts to save facilities like the Fast Flux Test Facility, where high security costs worked against private investment. But now an SAS team looking for change had surfaced the question. They were not merely stating an opinion, they had facts to back it up.

Nearly \$11 million was being spent on protecting government property, while losses hovered around 5\% of that amount.

Nearly $\$ 8$ million was spent for protecting classified materials. The costs were high not only because so much material had accumulated during 50 years of operations, but also because under the umbrella of protection, classified materials were stored in numerous locations and provided with multiple layers of protection-clearly, a prime candidate for consolidation.

At Hanford, these costs were part of a culture aimed at protecting the whole site, rather than focusing on protection of individual assets. The transition would work to change that culture.

The awareness that costs were high was not a new or earth- shaking discovery. But the Planning Team was able to present the facts in a way that gained attention. When they presented their findings to Wiley, he was surprised at the number and range of suggested changes. He did not argue with the logic of any individual recommendation. 
Rather, the number of changes taken together suggested that the work ahead was not a simple fix he could do with the left hand, while the right hand continued to run the SAS organization.

During January and February, Wiley and the Planning Team began a series of presentations. They began with presentations to the RL security managers and other RL managers who would be affected. They presented the information to the assistant manager who was responsible for Safeguards and Security; to other assistant managers; and finally to Manager Wagoner. Once they reached that level and achieved a consensus on the overall direction, they made presentations to the contractor SAS managers and then to the directors and presidents of the contractor companies.

Next they went to DOE Headquarters and made a series of presentations, beginning with the director of the Office of Safeguards and Security, followed by the director of Security Affairs. They also spoke to an assistant to Leo Duffy, the head of the Office of Environmental Restoration and Waste Management that now funded the new mission at
Hanford. The reaction was

favorable. But it became apparent to Wiley and the Security Planning Team that to move forward swiftly with so many major recommendations, they would need a high-level leader from RL with connections to Headquarters and to upper management on the site.

Manager Wagoner, agreed to find someone who could best carry the effort forward. He asked Joe Wiley to provide a list of recommendations. Included on the list that Wiley provided was Bob Rosselli.

Rosselli agreed to take the job. As part of the agreement, the SAS program began to report to him in his position as Assistant Manager for Administration. With that understanding achieved, Rosselli began work on what came to be called the Security Transition Project.

\section{Security Transition Project}

The name was important. Rosselli wanted to run this effort as a project with a formal plan. His staff set to work preparing the initial plan, beginning with a vision statement.
By March, the ideas for change that the Planning Team had presented in January and February were captured in writing. The result was the first work breakdown structure, a logical hierarchical structure for ordering tasks and subtasks. Once in this form, the ideas could be put into statements of work, funded, and executed when the time came.

Preparatory work continued during April. The actual project began in mid-May and continued through June. The results were evaluated in July and once again presented to management locally and to Headquarters in August.

The short time allotted for the Security Transition Project was by plan, not by accident. Rosselli was able to attract high-level leaders partly because they knew that their commitment had clear boundaries. Also, a heightened energy level develops when effort is focused on a near-term goal. Finally, if any work was to begin at the start of the next fiscal year, it would have to be included in funding decisions that would be made in July and August of 1992. 


\section{Transition Timeline}
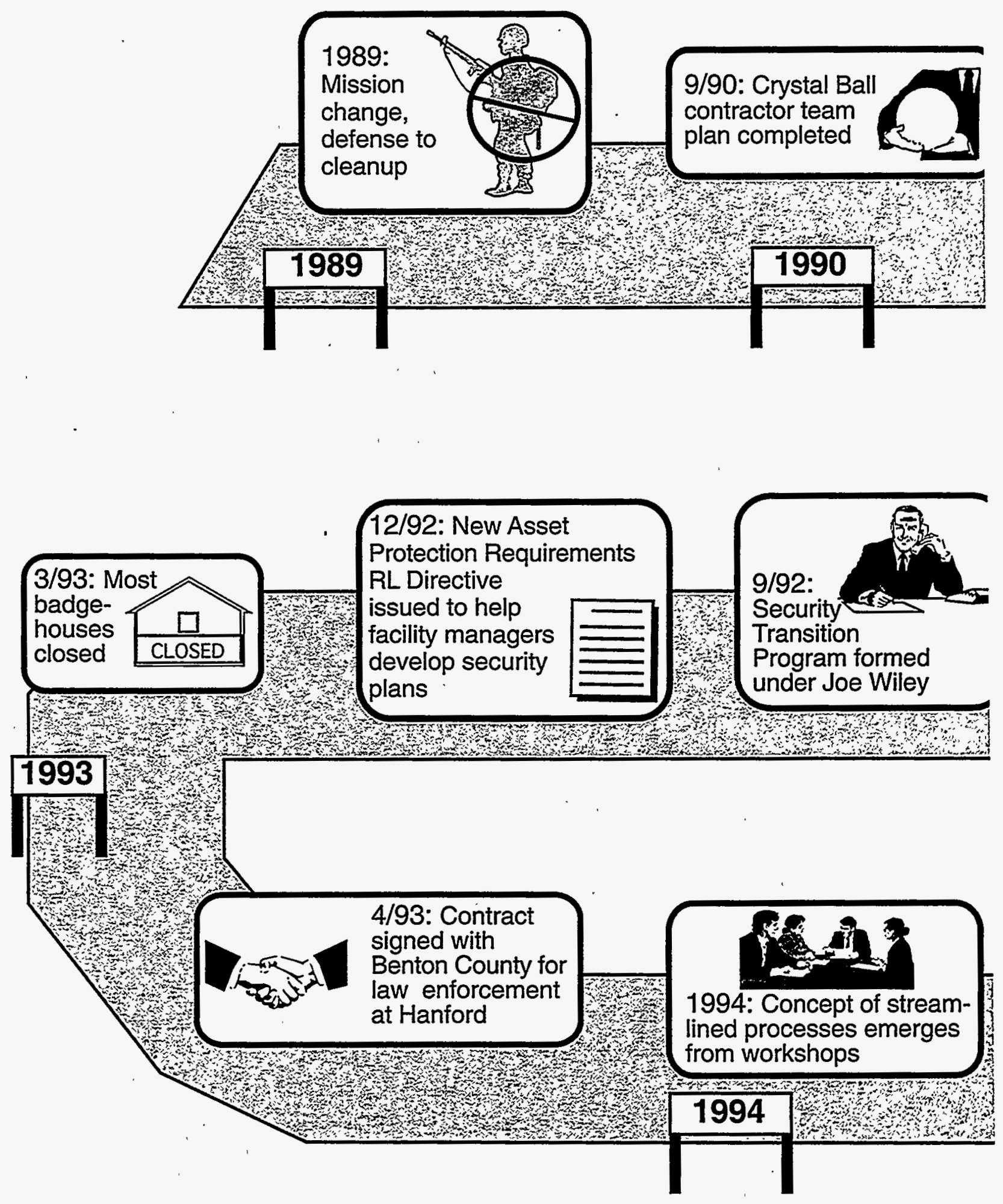


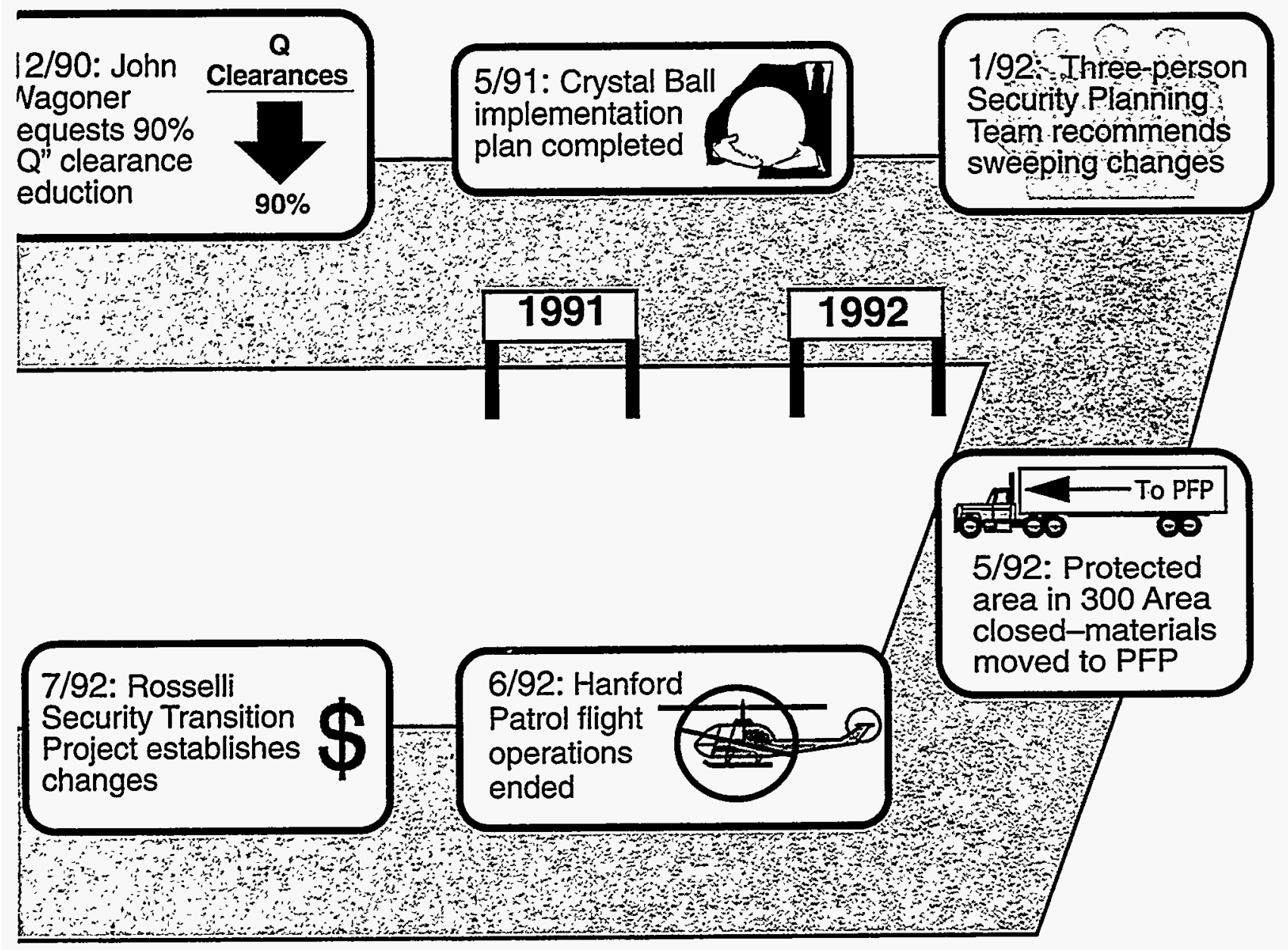

7/94:

$Q$ clearances Clearances reduced by $83 \%$; total clearances reduced $66 \%$
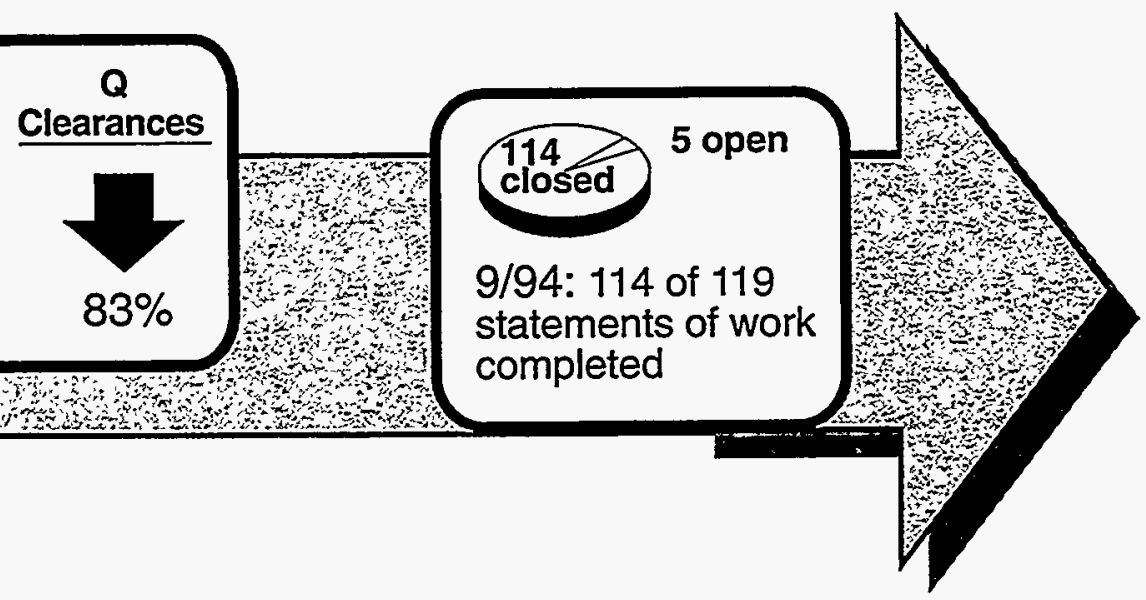


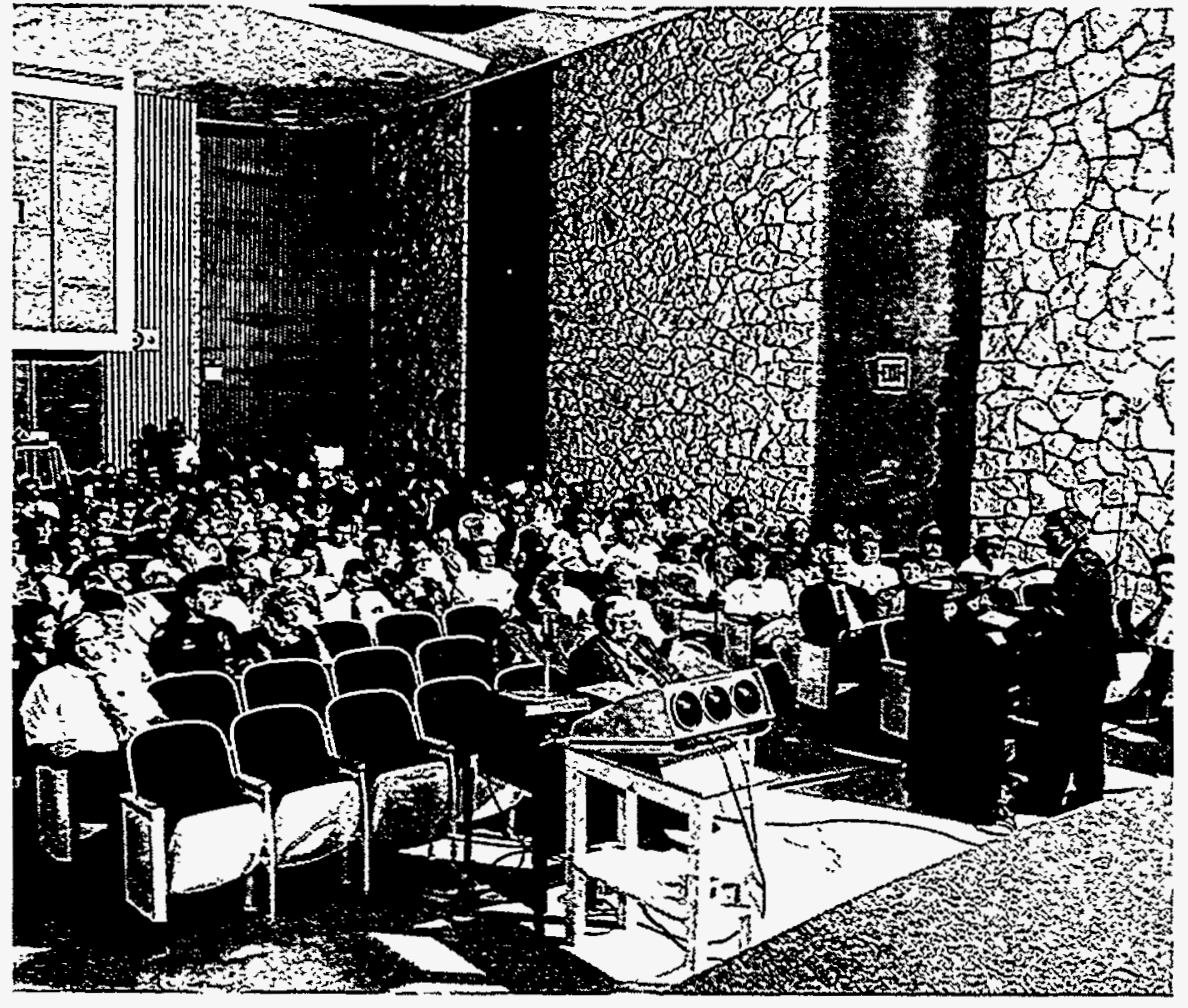

Outreach was an important part of the transition. In meetings like this, the coming changes were explained to interested employees.

The key focus of the Security Transition Project was to examine whether the list of items in the work breakdown structure were doable. If they were doable, what was the scope and cost to make the changes? What would the savings be?

Task summary sheets were developed to capture this information. Once assembled, the team would go out and gather their information and report it on these forms. They would state an issue, make recommendations, and estimate required funding in the space of one or two pages. This approach fit the short timing for the exercise.

A project leader was selected for each of three areas: threat, transformation, and systems. Each project manager was looking at security from an outsider's perspective. This perspective was in contrast to the previous effort, the Planning Team, that had an insider's perspective. Outsiders did not have preconceptions about how security should be set up.

Each member was an effective manager with a unique viewpoint. The weekly meetings of the management team with Rosselli were lively. Strong views were encouraged and often stated.

Ideally, key topic areas should be looked at sequentially. The threat should be examined; the policies developed or transformed in response to the threat; and the systems developed to meet the resulting needs. In fact, all three projects were going on at the same time under the same compressed schedule. The team continued its intensive task of scoping the work. Staff went out and gathered information on the various topic areas and then brought back their results and discussed them. Gradually, several hundred pages of documentation were compiled.

When the work was completed, Rosselli read through the material and brought the team leaders and key players together. In a workshop atmosphere, they went through each individual item and reached a decisions.

\section{Outreach}

From the beginning, Rosselli believed that public outreach and involvement were 
important to the success of the security transition. The program included aspects of public involvement, although six weeks was not enough time for a full public involvement program.

Many groups and individuals were contacted personally and letters were sent out to numerous other groups. As part of the effort, the team prepared and presented information to management, employees, and the public. Rather than marching ahead with transition and waiting for people to react, the transition project sought to provide the information and offer opportunities for various publics to comment on the proposals up front. They responded to each comment received.

\section{Material \\ Consolidation}

As the task force geared up, two important changes, long in the works, were coming to fruition. Special nuclear materials were being moved out of the 300 Area and the Hanford Patrol Flight Operations were being closed down.

Moving the material was an old idea. What prevented that happening sooner was a combination of factors. The plan was to move the fuels work to the 400 Area. However, the future of the Fast Flux Test Facility began to be questioned and that uncertainty, plus the cost of contaminating new facilities for a potentially short project, made the move questionable. In addition, projects kept arising that DOE wanted to supportkeeping the 300 Area fuels operation in business.

One contractor manager stated that when people questioned the high cost of security, he pointed out that the only ways to reduce the cost were to shorten the perimeter or take more risk. By removing nuclear materials from the 300 Area, the perimeter around special nuclear materials was reduced significantly.

The perimeter around special nuclear materials has continued to shrink. The Hanford Site had six protected areas in 1984. Ten years later, the two remaining protected areas include a very small portion of the 400 Area, (where the Fast Flux Test Facility is located) and the Plutonium Finishing Plant in the 200 Area. The Fast Flux Test Facility is not a credible target for terrorists. The material is difficult to access and not in an easily portable or usable form.
Therefore, the most credible target for an outside attack or internal diversion is the material stored in the 200 Area at the Plutonium Finishing Plant. Shrinking the perimeter that must be protected to one credible target significantly reduced the level of protection required across the site.

\section{End of Flight . Operations}

Two helicopters had been brought to the site to meet requirements for delivering a Special Response Team to defend protected areas that were spread out over some 40 miles of territory. If the 308 protected area could be closed down, and if only the Plutonium Finishing Plant and the Fast Flux Test Facility remained, then the rationale for maintaining the helicopters was weakened. During May 1992, the remaining materials in the 308 Building were finally moved to the Plutonium Finishing Plant in the 200 West Area.

An assessment of the helicopter issue was completed on April 1, 1992. The study, which was prepared by the Westinghouse Hanford Company and Los Alamos Technical Associates, concluded that while the helicop- 


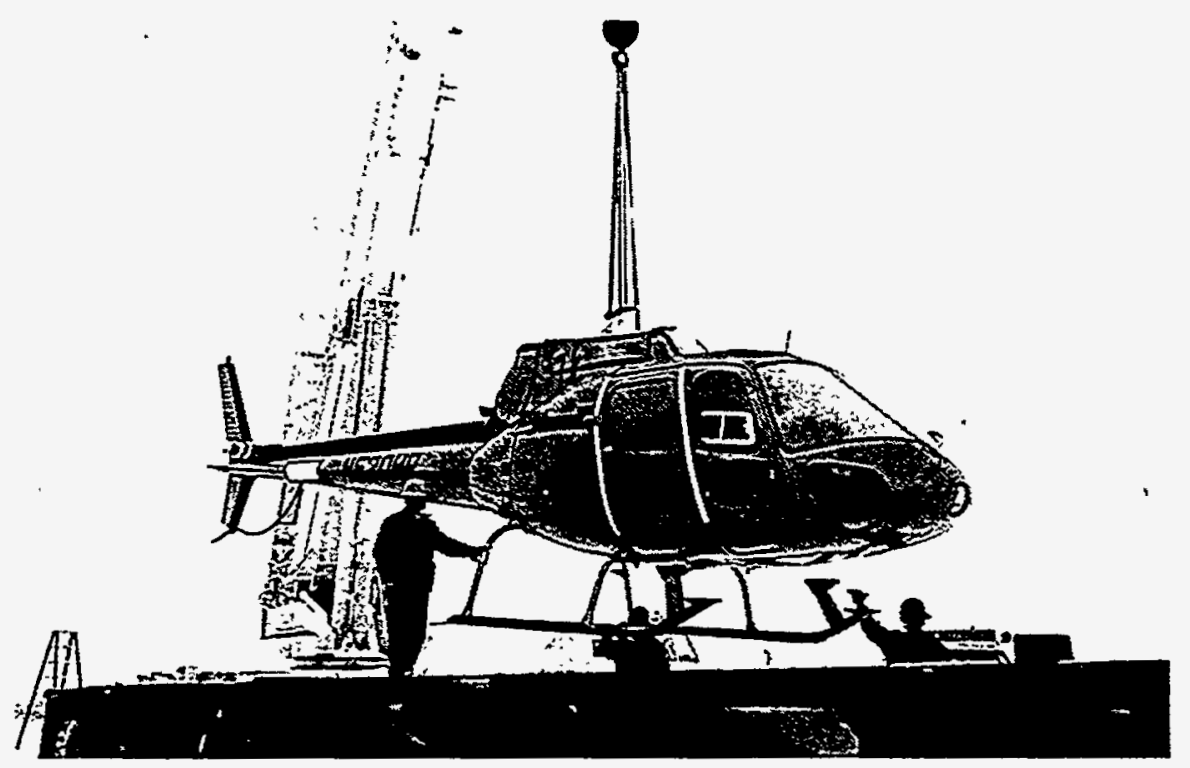

Once protected areas that stored special nuclear materials were reduced to two, Hanford Flight Operations were terminated.

ters provided many security benefits that enhanced the overall SAS posture, once the high security interests in the 308 Building were moved to the Plutonium Finishing Plant, the "compliance justification for continued operation" of the helicopters would no longer exist. The study did suggest that other applications of the helicopters be looked at.

On June 8, Manager Wagoner announced the decision to end the aerial patrols of the site by helicopter. The helicopters were soon prepared for shipping and in about six months were transferred to the U.S. Forest Service. The annual cost reduction for Safeguards and Security was about $\$ 1$ million. tion team recommended that the guards not be replaced by automation.

\section{Thinking the Unthinkable}

Once someone could think of removing the guards, it became possible. With the nuclear materials in place, it was unthinkable. During the defense mission, the focus of attention was on better and better protection. Once the focus switched to making changes, improvements, and cost savings, many things that were unthinkable in the past became thinkable and then doable.

As the Security Transition Project completed its work, a new idea surfaced. The team charged with looking at automation began considering how to automate the entrance to the 300 Area and other entry points to the site. Automation experts typically begin by asking the question: Why automate? They looked at the automation plan and questioned whether automation could really replace humans. But they also questioned whether either guards or automation was needed. After all, with nuclear materials consolidated, all that would be left to protect was ordinary government property in most areas. Therefore, the automa-
Thus the will to change grew from a.seed to a plant that would flower under the Security Transition Program Office into the many changes to security and a model for changing other programs at Hanford.

\section{Initial Benchmarking}

The vision developed by the Security Transition Project team was of industrial-style security, supplemented to protect remaining nuclear materials and classified information. But Hanford had no experience with industrial 

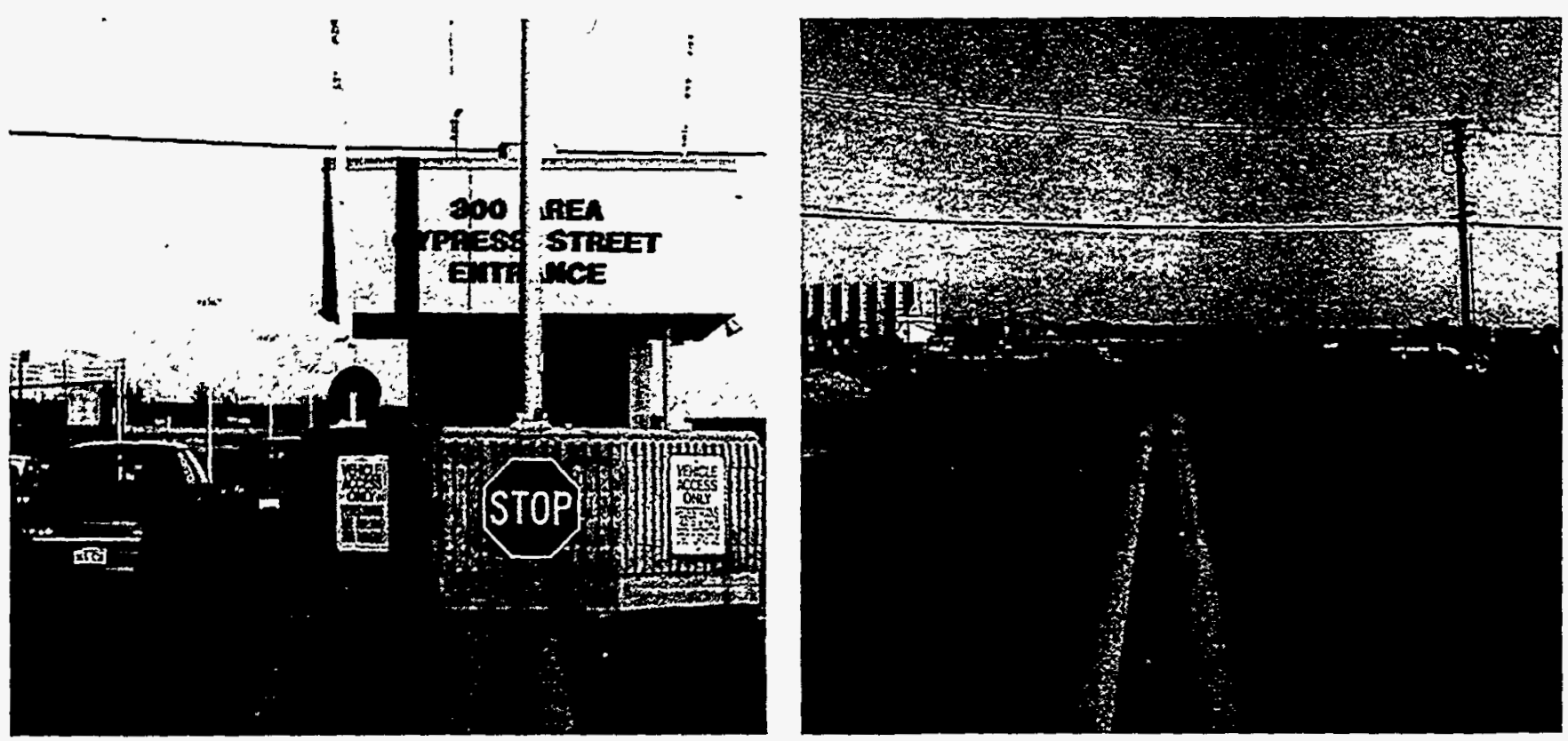

Formerly, when entering a work area, employees were checked through a badge house by the security patrol. Now signs, locked doors or receptionists, and random protective force surveillance provide industrial-style security at Hanford.

security, so contacts were made with several companies including Westinghouse, Microsoft, and Boeing. Boeing's Seattle site, though much different thañ Hanford in many ways, was comparable in some key aspects-its large size, for example, and the fact that it dealt with classified information for its defense contracts.

Several visits were made to the Boeing company and discussions began on how to apply the lessons learned there to Hanford. For example, the team witnessed the way Boeing protected classified information for its defense contractors. By seeing another site that was meeting require- ments with fewer layers of security, they quickly recognized the redundancies that had developed at Hanford. Boeing was also focused on becoming very customeroriented. They wanted to protect property while at the same time welcoming customers from around the world. They were in the process themselves of reorganizing security to meet this need and their work was informative to the Hanford team.

\section{Defining the Next Step}

The findings of the Security Transition Project were presented to Hanford management during July and August.
In August, presentations were made to DOE Headquarters. The presentations covered the overall concepts of replacing the umbrella of security with limited area islands and a more open site. However, what got upper management's attention was the estimated savings of $30 \%$ to $50 \%$ of the FY 1992 budget of about $\$ 67$ million. A letter from Manager Wagoner dated September 8, 1992, mentions that Headquarters endorsed the security transition proposed for the Hanford Site. Further confirmation arrived on October 1 in the form of a letter from Leo Duffy, Assistant Secretary for Environmental Restoration and Waste Management. 
Both letters were included in the Multi-year Program Plan for security transition dated November 1992.

Wiley was appointed to head the security transition. Because of his security background, he viewed himself as the builder of an organization, who knew best how to fix what needed fixing.

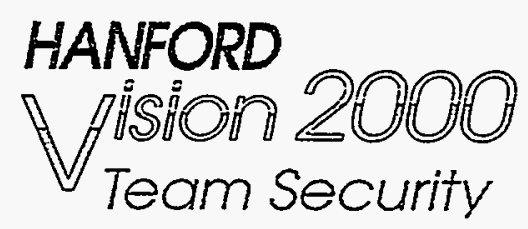

\section{The Security Transition Program Office}

The vision for security transition was already developed when the Security Transition Program Office (STPO) opened its doors for business on September 9, 1992. The vision was one of industrial security and customer service for most of the site, supplemented by effective protection of remaining nuclear materials and classified information. It was a vision soon shared by the team developed to implement the changes.
Employees and the press were invited to attend separate briefings on the security transition on September 15, 1992. An article appeared in the next day's Tri-City Herald headlined, "Vision 2000 will trim security staff, costs." A longer article appeared in the September 21 Hanford Reach.

The article listed a number of coming changes: eliminating manned protection of selected badge houses, developing an entry center, consolidating alarm monitoring systems, consolidating dispatch centers, reducing classified information, developing a policy for protecting property, upgrading protection of special nuclear materials and evaluating the use of smart cards-microprocessor-based credentials that store information electronically-to potentially replace existing badges.

Clearly, the STPO opened with its mission and vision ready to roll out to the public. Several years of groundwork led up to this moment. When the STPO opened, it consisted of three DOE staff members. From the first, the vision was to involve a cross-contractor team in making the changes. Staff were pulled in from across the site over the next few months. In all, about forty staff members made up the team by January 1993.
The office was to last for only two years and was empowered to make change happen. It attracted people who believed change was needed and who tended to be self starters with little love for red tape. Early on, the tone for the organization was set in a procedure called the rapid implementation process (RIP). The acronym RIP stated the message of the document: The STPO would deal with obstacles to change, not by stopping work, but by going forward around the obstacle, assuming it would be fixed later. The feeling was that change needed to happen quickly or it would be swallowed up whole by the forces supporting the status quo. In the end, RIP was set aside in most instances for a more methodical approach — but the idea of making change quickly continued to be viewed as critical to success for a program with a two-year lifetime.

The initial assignment was to "do the access control changes and everything else." Everything came to include some 119 statements of work. But access control had the priority. It was a high-cost item that could be changed relatively easily. Changes affecting other organizations would be more difficult. 
Balancing the "go forth and conquer" attitude was Wiley's belief that things should be run through a process, and the process should gather data and lead to objective outcomes. The process would provide a defensible basis for decisions. Using a process did not necessarily mean going slow. In September, the STPO took some first steps: working with RL SAS to end badge checks of people exiting the site, working on a procedure for facility managers to use in devising their own security plans for assets, and setting the schedule for removing the Hanford Patrol from its role in controlling access to several areas.

The schedule called for the end of access control by Hanford Patrol staff at the gates to the $300,400,100,200$ East and 200 West areas, and the Federal Building. Because of transportation regulations, manned access control would be retained at the Wye and Yakima barricades-badge houses controlling entrance to the reactors in the 100 Areas and processing plants in the 200 Areas. The changes were scheduled between October 1992 and the end of March 1993, and the schedule was adhered to closely with exceptional support from the contractor security staff.
To manage the human resources impacts of the access control changes, a job placement assistance office was opened within Westinghouse Hanford Company, and displaced workers were given priority for jobs across the site. Some 70 people were placed by the office during the few months it operated. Continuing declines in Hanford Patrol staff were mostly managed through attrition. The staff was above 400 in 1992 and declined to about 225 near the end of the security transition. Workers had the option of other jobs at Hanford that were opening up in the cleanup effort.

\section{Safety Issues}

A key issue in removing the badge houses was safety. It became clear during the planning stages that security was carrying part of the burden for other areas-particularly safety. If the public was prevented from entering the Hanford Site, the job for safety was that much simpler. If the gates were open and only signs prevented people from entering, the safety of any unauthorized visitors became a concern.

The STPO hired a safety expert who walked the site and applied an existing procedure for establishing risk to the safety issues at each area. The conclusion for all areas but one was that the risk was low and the modifications needed were minor. Management agreed to assume the low risks and the changes went forward. The exception was that the Wye and Yakima barricades remained in place. If they had not, an agreement with the Department of Transportation for shipment of wastes on the Hanford Site would no longer apply. The result would be significantly higher costs for those shipments.

\section{A New Procedure to Protect Assets}

Change tends to have ripple effects that lead to other changes. Aware that the access control changes made access to facilities easier, the STPO was working on new rules for protecting facilities and property. The rules were being collected in a procedure called "Asset Protection Requirements." They would not apply to most nuclear materials, but would cover protection of other government property.

The requirements went hand in hand with the open access approach. In the new order, gates would stand open. Signs warned the public not to enter, but clearly, the perimeter fence was no longer secure. So asset owners, usually represented by 


\section{Schedule for Closure of Badge Houses}

The security transition quickly changed the way most employees entered the site. The end of access control by Hanford Patrol occurred as follows:

- December 1, 1992-300 Area South and 100 N Area

- December 23, 1992-400 Area

- January 20, 1993-200 East and West Areas

- March 3, 1993-300 Area North

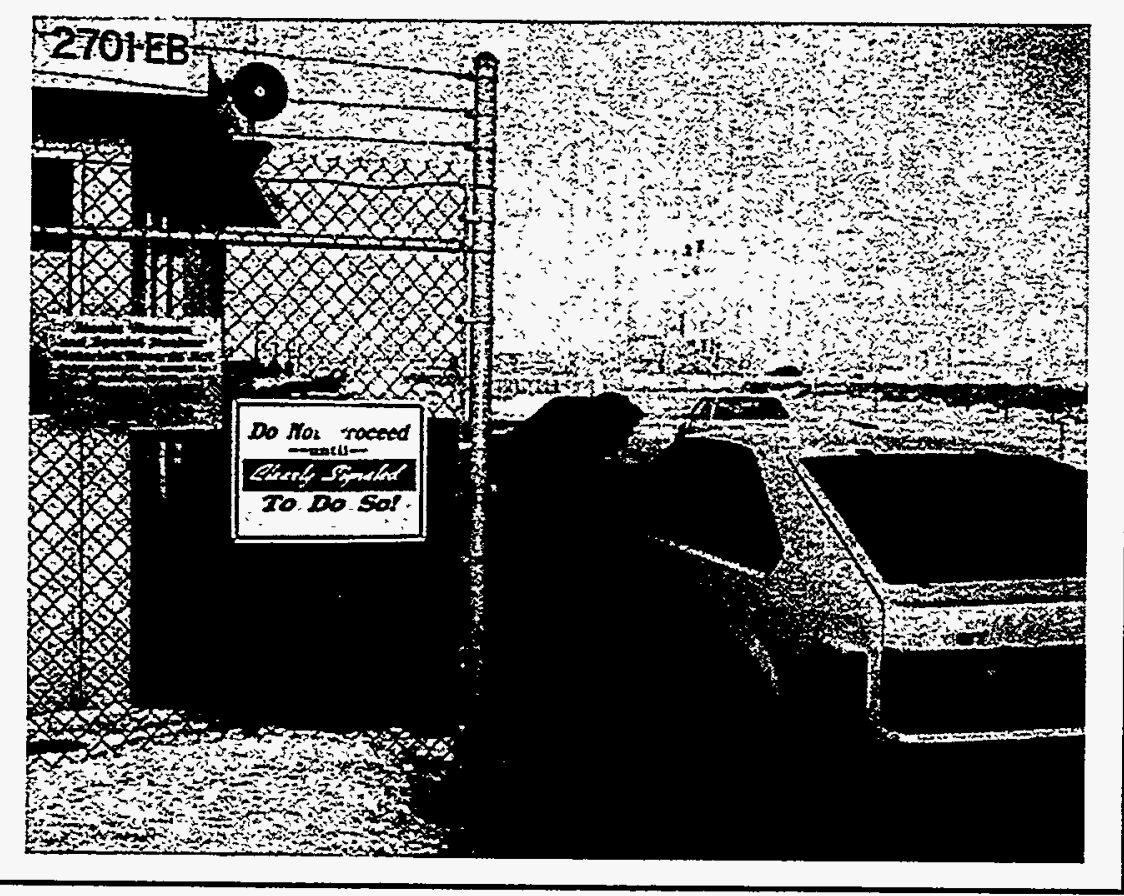

the facility managers, had to take more responsibility for security at the asset location. That could be within a building, but it could also include a room within a building. Secure areas, called limited area islands, could be set up as a single office if necessary. The flexible use of limited area islands meant most of the site could be accessed by staff without security clearances. New workers could be brought in for the cleanup work without first going through the process of getting a clearance.

Access to assets still needed to be controlled. Suitable options included locked doors, automated access controls, or receptionists. The asset owners were given a new procedure that allowed them to sort through these options and evaluate the risk of loss for their assets as low, medium, or high. Then they could work with a security representative to design a protection plan.

Guiding this change was the view that security should become a customer-oriented organization. Asset owners would be viewed as customers, who could use the services, or come up with a plan on their own. Conceivably at some point, customers might shop for security services, seeking the best deal at the lowest cost.

Much of the thinking that went into the procedure on Asset Protection Requirements was borrowed from Boeing. One of their security experts helped draft the procedure in the first weeks of the program. The procedure was revised several times before it was issued and again after it was issued, when people had problems applying it in some instances. As the security transition was drawing to a close, yet another revision was in progress. The latest version will allow building managers additional flexibility in determining when identification badges must be worn in individual buildings. The procedure continues to be a living document that is being adapted to the changing situation. 


\section{Formal Business}

\section{Processes}

While access changes were a major focus, security transition was a much broader effort. In addition to two key projects, an entry center and a consolidated emergency dispatch center, plans included a review of virtually every security organization and effort to streamline security processes across the site. By the time the STPO opened its doors, a work breakdown structure had been created along with a draft Multiyear Program Plan. The program plan was soon finalized and stated in brief outline the mission, vision, goals, and objectives of the program.

An annotated copy of the work breakdown structure captured the main areas where work would proceed. As project managers were brought on board, they created more detailed statements of work for each item in the work breakdown structure. Project management software was purchased, schedules developed, and tracking of the work began. Some 105 work packages were tracked initially. The number grew to 119 during the security transition. For areas other than access control changes, much groundwork needed to be

\section{Statements of Work}

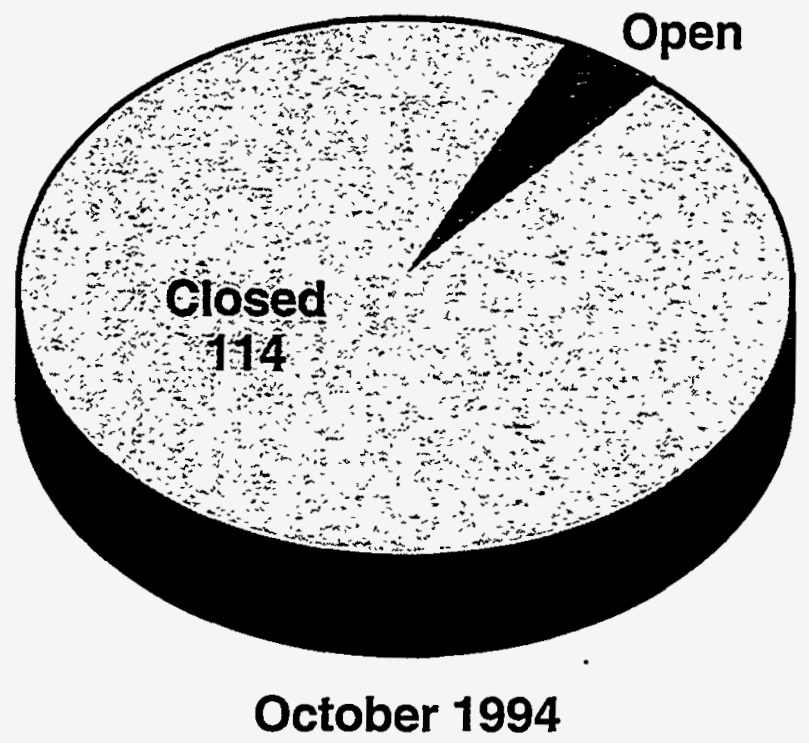

October 1994 done. Over the first year, many workshops were held to gather data and to prepare plans and reports in support of change efforts.

During year two, the time came to reach decisions and implement changes. A formal decision process was devised to guide the flow of work through various reviews to a decision and implementation. The process spells out the interfaces between RL, STPO, STPO support teams, and Hanford contractors.

These formal processes provided a structured approach to change and a way to effectively track progress. By October 1994, only five tasks remained to be handed off to the Safeguards and Security organization for completion.

\section{Open Site Controversy}

During the planning phase of transition, people began to think of the changes as opening up the Hanford Site. The badge houses would be removed, locked gates would be opened, new gates could be punched in formerly solid fences to allow employees free access to areas and buildings. The buildings would, however, be locked. Moreover, the public would be excluded. When the media asked what security transition would mean for the general public, the 


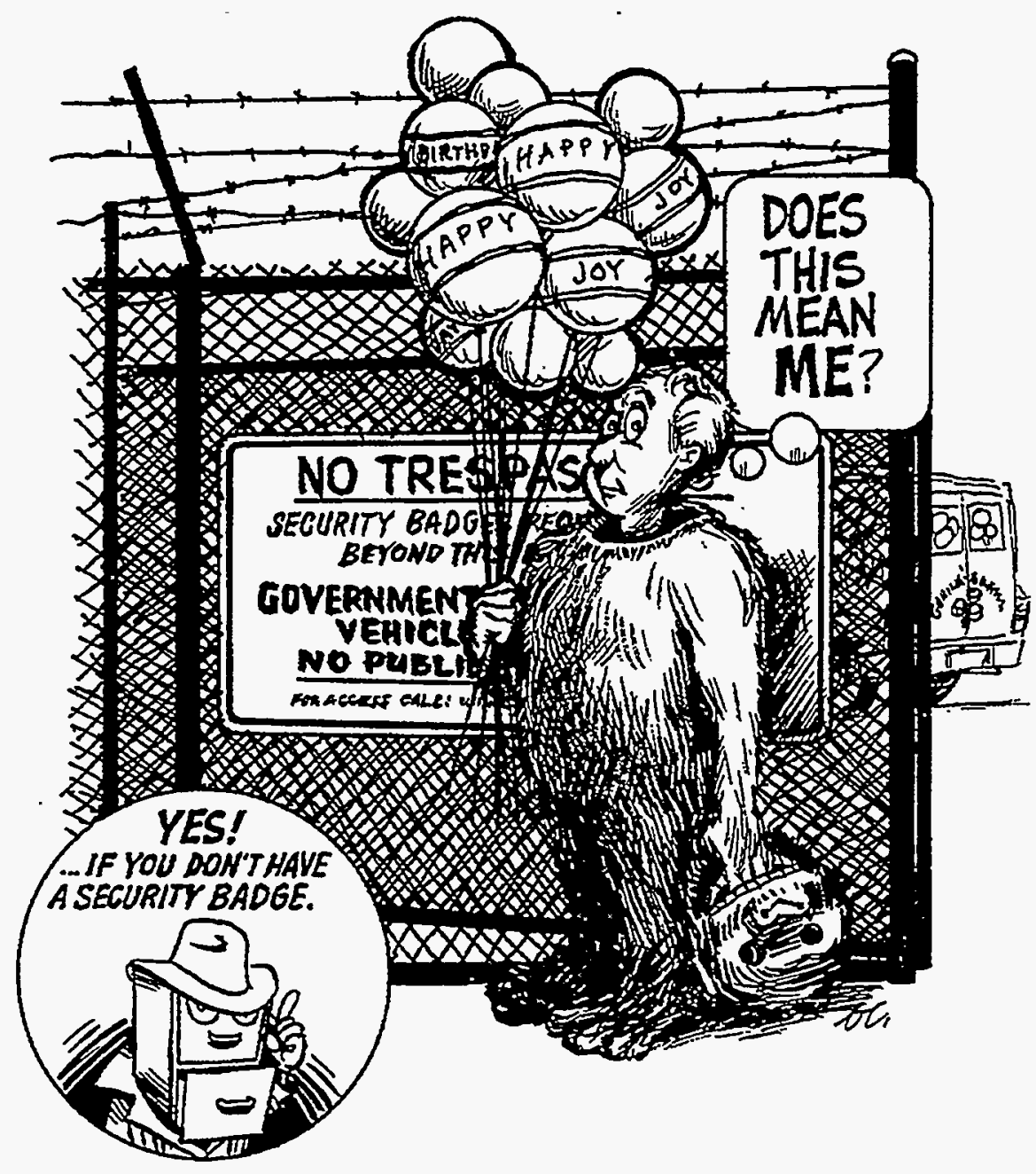

answer had to be, "Not much in terms of access." The public would still need a badge and an escort.

Early announcements talked about an open site, but by February 1993 retractions appeared in the Hanford Reach newspaper. The Hanford Patrol began to report pizza and flower delivery trucks driving into the 300 Area. Nonemployee spouses were identified picking up their employee mates at the building instead of at the perimeter fence. These incidents were reported and generally treated as growing pains for the new approach to security. Several articles and cartoons appeared in the Hanford Reach to help alert people that the site was more open to employees, but not to the public.

The changes required some adjustments. Labor issues needed to be addressed. Buildings in the fenced areas that formerly were open to anyone going through a badge check, now were locked, unless the building manager decided to provide a receptionist. Visiting employees found some buildings more secure and less convenient to enter. More lighting was added to help employees feel safer when leaving work late at night, now that the Hanford Patrol was less visible.

A key benefit of the changes for employees was the added convenience. For example, in the 300 Area, a trip to photography to pick up a rush photo order formerly required a 10minute walk from the Wisconsin Street gate, now employees could park at the Apple Street Gate near the photography building. No longer were lines of cars waiting for a badge check before entering an area. These improvements have tended to improve morale and increase productivity.

\section{Capturing Savings}

A $\$ 5$ million budget was provided to operate the security transition during the first year. After that, the funding was to come from savings resulting from changes in security. The concept provides an incentive to save money - but a mechanism had to be developed to make it happen in a hurry. A change control procedure to capture savings from Hanford programs was developed. The procedure was designed to 
lange process in a rather than through tional sequential process. The result was rocess, which could long as six weeks, was ompleted in one

$\mathrm{g}$. The secure source of g made it possible to ad carry out the transiravings not spent on ion were returned to srd programs.

\section{jor Projects}

security transition took on major projects. One zct was to create an entry er and consolidate access ices there, the other, to solidate several 24-hour zrgency dispatch centers ) one center. The transition 1 some success in both as, although the plans anged during the implemenion process.

\section{ntry Center}

icture a large site with lusters of facilities dotting the tesert landscape. The plan is to lo major cleanup work ncluding earth moving and sleanup of mixed radioactive and hazardous wastes stored in tanks. Entry to much of the site has been controlled by checks at badge houses. Now those checks are going away, except at one or two remaining protected areas. Will it be safe to allow visitors to enter the site without any preparation? If not, should they enter at a central facility and get the information they need to safely access the site? Finally, if such a facility has to be built, can a number of security functions related to access control be consolidated in this facility and gain some efficiency? Such was the thinking that went into the concept for an entry center.

During the transition, things changed so that some of the rationale for a new facility went away. For example, because of safety concerns, the Wye and Yakima barricades remained in place, and they control access to the area where most cleanup will take place. The cost of a new facility was questioned. Workshops provided new insights into how to streamline the work independent of a new facility.

Moreover, the concept of a virtual organization-an entry center without walls-began to come into focus. An example would be in clearance processing. Initially, this was planned as fill-in work at a new entry center. The idea that developed during the transition was to create an electronic form to gather the data, distribute the form on the network, and collect the data from across the site within DOE.

Automation technology was changing other security functions as well-making a physical entry center less necessary. For example, badging information was becoming digital, suitable to being put on the network. These changes pointed out that security was in flux, and the time was not right to build a facility when the work was rapidly changing. Instead, as the STPO was completing its work, the entry center manager was looking at short-term improvements to processes and having some success.

Included in the improvements was integration of some of the 12 security databases. Some of the information on the databases was redundant and had to be manually crosschecked from time to time. This integration could not be completed in the two-year security transition, but the core of the work was to be completed in FY 1995.

A key reason for building an entry center was to provide improved customer service. A proposed redesign of the 3790 facility will provide an opportunity to test ideas for improved customer service. The original entry center 


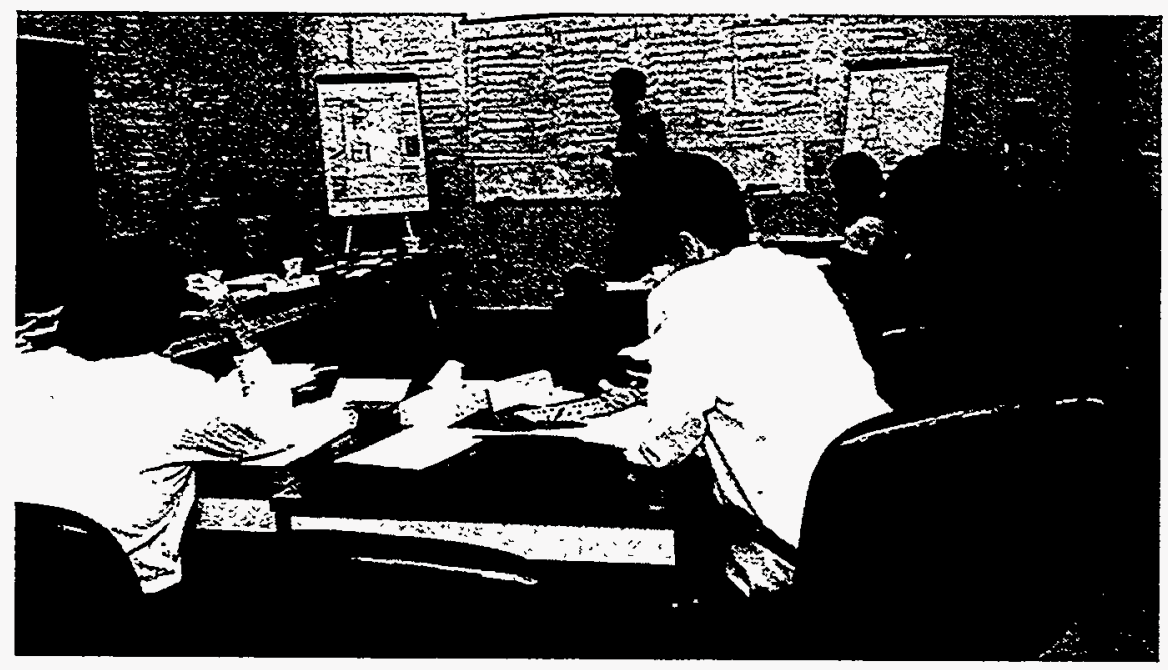

Workshops involve security employees in redesigning their business processes to be more cost-effective.

concept was of "one stop shopping" to fill the access needs of visitors. The redesign effort will provide opportunities to do this. Currently, customers may go to a counter to begin the badging process, then move to another room for a picture, and another room for fingerprints, to another part of the building where access control personnel provide information, to another room to receive a briefing or see a video and finally, to the badging counter. In the remodeled facility, these functions will be located together in distinct but adjacent stations. Such a setup allows more teaming among employees, who can be crosstrained in related functions. The redesign effort will improve productivity as well.

Although the entry center as originally envisioned was not built, the consolidation of services that was the principal goal of the entry center concept is making steady progress. At the beginning of transition, "the entry center". referred to a proposed facility. By the end of transition, the entry center referred to the effort to streamline security processes independent of a location.

\section{Dispatch Center}

In September 1992, the STPO began work on a consolidated emergency dispatch center for the Hanford Site. A review of the current situation showed four 24-hour dispatch centers on the site: the Patrol Operations Center, the Central Fire Dispatch Center, the Occurrence Notification Center, and the PNL Control Room. Several benchmarking trips showed examples of cities and an airport that had consolidated their emergency dispatch functions effectively. The hope was that Hanford could also benefit from a single consolidated center.

Several inefficiencies were identified in the current system. For example, the operation of the 911 phone number was complicated by the existence of separate dispatch centers for fire and patrol. First a call went to a patrol dispatcher who then contacted the fire dispatcher if the call was fire related. A single center for fire and patrol would eliminate this redundancy.

A complete consolidation was studied but was not achieved in the two-year security transition. However, an important step was taken with the decision to consolidate the Central Fire Dispatch Center with the Patrol Operations Center. As of July 1994, two locations were under consideration for the combined center-one is a new central fire station for the Hanford Site and the other is in the Patrol Operations Center in 200 East Area. The consolidation is estimated to cost about $\$ 2.8$ million and to pay for itself in less than six years. The cost savings, combined with improved operations, can be 
spected to provide an icentive to further consolidate ispatch services in the future.

\section{3enton County Sontract}

$t$ clear sign of the shift away rom a secretive, closed site at Janford was the signing of a zontract with Benton County for the Sheriff to provide law enforcement on the Hanford Site. For the first time in its history, the site was letting go of some of its command and control philosophy. In the 1940s, that philosophy had led the County to empower the Hanford Patrol to enforce Washington State law. Patrol could then control speeds on the roads of the large site and arrest violators without bringing any "outsiders" onto the site.

The downside was that the several hundred members of the Hanford Patrol had to be trained in state law enforcement, even though only about 10 at any one time would act as deputies. DOE liabilities were a concern. Also, carrying out law enforcement duties was complicated for Hanford Patrol by several issues: they were put in the position of arresting fellow employees; the process of getting warrants was unusually time-consuming; and testifying in court was

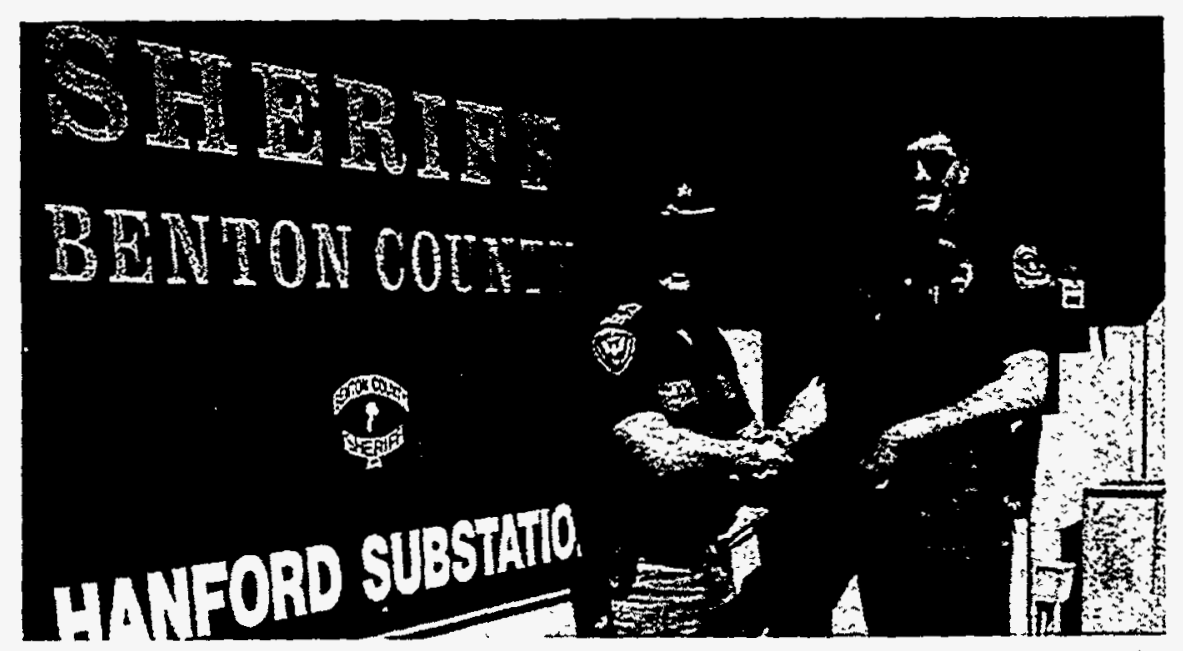

Traffic enforcement and criminal investigations for the site are now provided by the Benton County Sheriff's Office, a sign of the change to a civilian mission.

more expensive for Hanford Patrol than for the Sheriff's Deputies.

The result was an agreement to let the County handle law enforcement and to fund that work under a contract with DOE. A letter agreement with the County allowed for some preparatory work to begin early in the transition, and when the contract was officially signed on April 28, 1993, a Hanford substation of the Sheriff's Office was in operation.

As part of the change, the three dogs from the K-9 program were transferred to local law enforcement organizations. Two dogs were given to the Sheriff's Office and one to the Richland Police Department. The dogs were a useful addition to these organizations and were still available locally if their services were needed on the site.

To date, the new approach has worked well. For Hanford, this change is an example of the growing cooperation with County and City officials. It may signal the beginning of a trend toward purchasing services rather than operating as a self-sufficient entity at Hanford. Other site services are currently being reviewed to see if they too should be purchased off site.

\section{Culture Change}

Changing the way people accessed the Hanford Site was relatively simple to accomplish. But security transition was more than that-its leaders had a new vision for security. In addition to simplified access to work sites, 


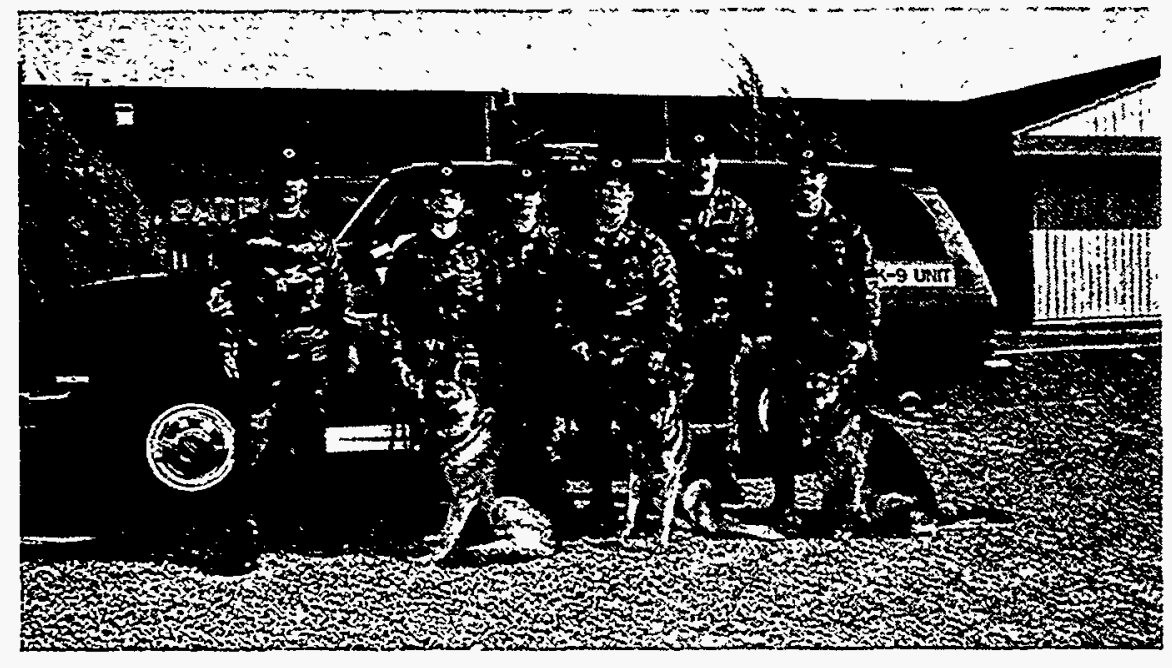

With the transfer of law enforcement to the Benton County Sheriff's Office, the Hanford $K-9$ Program ceased operation and the dogs were transferred to local law enforcement agencies.

they saw the need for a more service-oriented protective force. The change was summarized in the phrase "industrial security." The industrial culture was seen as one where security services met customer needs in a costeffective way. The end of the defense mission signaled a break with the paramilitary approach of the past. The ideal security officer in the new view might walk the halls unarmed, in civilian clothing, and with a smile greeting fellow employees. Cooperation and partnership would describe the new order.

On the other hand, the protective force that had developed to serve the defense mission was a highly trained, paramilitary organization, proud of being among the very complex, and ready to give their lives in the effort to prevent terrorists from escaping with nuclear materials. In this view, safeguards and security was Order-driven, a requirement not an option. When interviewed by an independent team of social scientists, the SAS management tended to brush aside questions about customers or customer service. They did not think in those terms. They did not see the defense mission as really over-not as long as nuclear materials existed on the site.

The STPO had one vision of security, line management within SAS had another. Recognition that changing from one culture to another was difficult came early in the best security forces in the DOE transition. Culture change experts discussed with the STPO staff how changing an organization's culture is a long-term venture and one at which many businesses have failed during repeated attempts at change.

Efforts were made to evaluate the vision of those leading the transition and to establish how successful the transition was in spreading that vision across the site. The results showed that while the STPO successfully communicated the vision within the program office, getting the SAS organization to buy into the new vision remained a challenge.

Part of the reason was that SAS came to view itself as an organization under attack. The tendency, one manager noted, was to circle the wagons. While the STPO viewed its work as the forward-thinking implementation of a new improved vision, the SAS saw the many jobs being eliminated and many believed that the overriding concern was costcutting.

One SAS manager has noted that any effort that made such dramatic changes was bound to stir strong emotions. Meanwhile, on a small scale, he is seeing 


\section{Safeguards and Security Budgets}

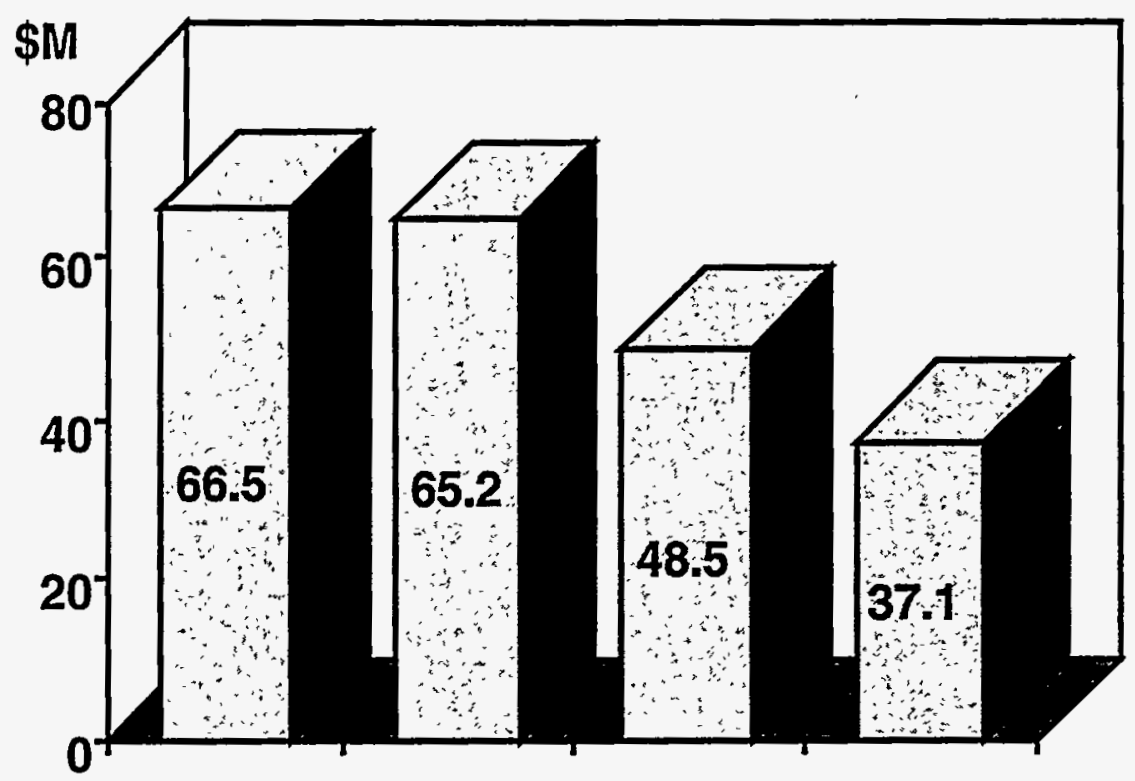

\section{FY 1992 FY 1993 FY 1994 FY 1995}

Dollars saved in the transition to industrial security will support environmental restoration and waste management.

positive gains in teamwork, empowered employees, and cooperation among contractors as a result of security transition. In addition, one contractor security manager noted that although he disagreed with the tactics used, the transition needed to be done, and the STPO accomplished much more than the contractors would have, had they been asked to do transition on their own.

The final question is whether the new vision for security will catch on within the SAS organization after the STPO is gone. To expand acceptance of the new vision will require continued efforts at education and at developing an acceptance of a role for security that is in keeping with the site's current and future missions.

The SAS organization is still in the midst of adjusting to the significant changes of the past two years. For the time being, the culture change effort has been closed out. But culture change as an issue for security and for Hanford will not go away. The Cold War ended in 1987. The mission changed at Hanford in 1989. In 1994, the amount of plutonium at $\mathrm{DOE}$ sites was declassified. In July 1994, high-level Russian visitors toured the vault where plutonium is stored at the Plutonium Finishing Plant. The
International Atomic Energy Agency began taking control of one ton of plutonium stored at Hanford. Clearly an era of secrecy has ended. What is not yet clear is how fast the culture will adapt to a changed world. Certainly, security transition was a step in the right direction.

\section{Savings}

The total transition will have cost less than \$14 million to reduce the SAS budget by more than \$29 million, roughly a reduction of two dollars for every dollar spent. Of course, the cost savings will continue to accumulate in the form of lower SAS budgets in years to come. The total SAS budget at Hanford in FY 1992 was $\$ 66.5$ million. As a result of the security transition activities, the FY 1994 budget has been reduced to $\$ 48.5$ million. The current projected SAS budget for FY 1995 is $\$ 37.1$ million. The significant drop in budget could not have occurred without the efforts to consolidate nuclear materials and classified information and the transition toward industrialstyle security.

In FY 1993, the STPO had a total funding of $\$ 12.2$ million available. The available funding consisted of seed money provided by $R L$ ( $\$ 5$ million) and savings from 
STPO change requests and underruns at the end of the fiscal year. Total expenditures of the STPO were only $\$ 5.2$ million. A total of $\$ 6.3$ million was passed back to RL programs in July and September. The remainder, $\$ 700$ thousand, was used to fund a portion of the Benton County Sheriff's Office contract.

In FY 1994, funding was $\$ 9.5$ million. In September, $\$ 0.6$ million was passed back to Hanford programs.

Drops in staffing were similarly significant over the two-year transition. In FY 1992, the SAS function on the Hanford Site had 737 personnel assigned to it. By September 1994, that number was reduced to 496 .

At the beginning of FY 1993, the STPO identified 105 statements of work that needed to be completed by the end of September 1994. That total increased to 119. At the end of July 1994, the STPO had completed 95 of the items. The STPO completed all but five items by the end of FY 1994.
Transition

as a Model

Security transition was clearly

a success in terms of cost savings. Concerns about the federal budget deficit have put pressure on DOE and other agencies to reduce costs. A study related to a two-day standdown across DOE's cleanup sites noted that DOE's costs for environmental restoration work were higher than other government agencies, not to mention private industry. As Hanford renegotiated the Tri-Party Agreement with Washington State and the Environmental Protection Agency, the three parties reached a side agreement to save some $\$ 1$ billion at Hanford over five years. Other efforts looked at reducing DOE overhead costs.

The security transition was a useful example for Hanford of effective cost savings in one area. Joe Wiley, who managed the Security Transition, became head of the Strategic Transition Initiatives Division, aimed at seeking similar savings in other areas. Thus, security transition has served as a model for additional cost - savings efforts aimed at making Hanford more effective and efficient in its missions.

\section{Validation}

During May 1994, Hanford's Safeguards and Security program underwent an extensive inspection and evaluation. Despite sweeping changes to security at Hanford, the comments on the security transition and its management were positive. Therefore, the inspection and evaluation was viewed as validation that the transition accomplished its goal of aligning security with a new mission while maintaining an effective program.

The validation made Hanford's security transition a model for use throughout the DOE complex. In a letter, Ed McCallum, head of Safeguards and Security for DOE, said, "...you have written the first chapters to the book of transition that will be our guide for years to come." 


\section{Contact James Spracklen, Director, Safeguards and Security Division MS A6-35 (509) 376-7441}

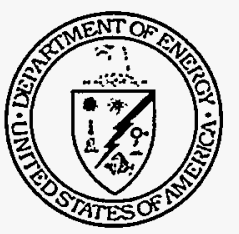

U.S. Department of Energy Richland, Washington 99352

RL-D95-002 1/95 


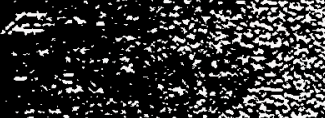

10

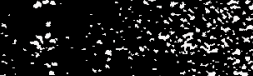

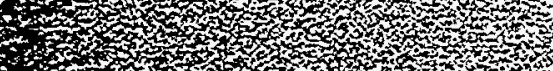

titis

1.

.

s.t.

H

\begin{tabular}{c|c|}
6 \\
6
\end{tabular}

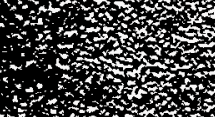

3
8

3.

tit:

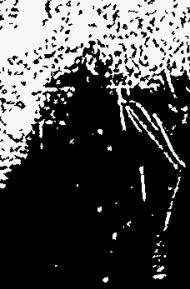

\%

(t)

4
3

$+2$

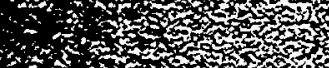

45

os

astos

4.

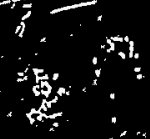

4.

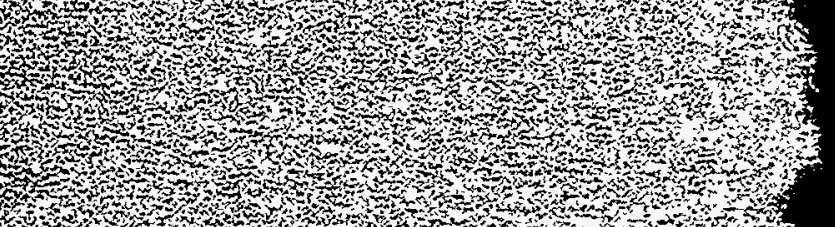

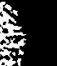

